\title{
Sweet Corrosion Inhibition on API 5L-B Pipeline Steel
}

\author{
Mahmoud Abbas Ibraheem, ${ }^{1}$ Abd El Aziz El Sayed Fouda, ${ }^{2}$ \\ Mohamed Talaat Rashad, ${ }^{3}$ and Fawzy Nagy Sabbahy ${ }^{1}$ \\ ${ }^{1}$ Department of Metallurgical and Material Engineering, Faculty of Petroleum and Mining Engineering, \\ Suez Canal University, Suez, Egypt \\ ${ }^{2}$ Department of Physical Chemistry, Faculty of Science, Mansoura University, Mansoura, Egypt \\ ${ }^{3}$ Department of Integrity Management, United Gas Derivatives Company (UGDC), Port Said, Egypt
}

Correspondence should be addressed to Mohamed Talaat Rashad, rtalat2005@yahoo.com

Received 20 September 2012; Accepted 11 October 2012

Academic Editors: M. Carboneras and Y. S. Chang

Copyright (๑) 2012 Mahmoud Abbas Ibraheem et al. This is an open access article distributed under the Creative Commons Attribution License, which permits unrestricted use, distribution, and reproduction in any medium, provided the original work is properly cited.

Corrosion inhibition and adsorption behavior of two triazole derivatives on API 5L-B carbon steel in $\mathrm{CO}_{2}$-saturated $3.5 \% \mathrm{NaCl}$ solutions was investigated using potentiodynamic polarization, EIS, and EFM techniques. Specimen surfaces were characterized using SEM, EDX, and XRD. Results show that the two compounds are mixed-type inhibitors and inhibition efficiency increases with increasing concentrations. Adsorption of the two compounds chemisorption and obeys Langmuir adsorption isotherm. Activation energy and thermodynamic parameters were calculated. Surface analyses confirm the formation of iron nitrides on the metal surface which supports results obtained from previous techniques.

\section{Introduction}

Carbon dioxide which is present naturally in oil and gas wells is injected purposely into wells to enhance oil recovery. $\mathrm{CO}_{2}$ corrosion, also known as "sweet corrosion," is one of the major problems in oil and gas industry, costing billions of dollars every year. Great efforts must be expended in corrosion control for safety, business, and environmental considerations.

Sweet corrosion is caused by the presence of carbon dioxide $\left(\mathrm{CO}_{2}\right)$ dissolved in water to form carbonic acid $\left(\mathrm{H}_{2} \mathrm{CO}_{3}\right)$. Corrosion increase as the concentration of $\mathrm{CO}_{2}$, system pressure, and temperature increase. This corrosion is typically slow, localized and results in pitting attack. Pits are very difficult to detect because of their tiny size and the corrosion products that cover them.

In oil and gas production and processing industries, corrosion inhibitors have always been considered the first line of defense against internal corrosion. Inorganic inhibitors, such as sodium arsenite $\left(\mathrm{Na}_{2} \mathrm{HAsO}_{3}\right)$ and sodium ferrocyanide, were used in early days to inhibit carbon dioxide $\left(\mathrm{CO}_{2}\right)$ corrosion in oil wells, but the treatment frequency and effect- iveness were not satisfactory. This led to the development of many organic chemical formulations that frequently incorporated film-forming amines and their salts.

In this work, the corrosion inhibition and adsorption behavior of Itraconazole and Fluconazole compounds on API 5L-B carbon steel in $\mathrm{CO}_{2}$-saturated 3.5\% NaCl solutions was investigated using potentiodynamic polarization, electrochemical impedance spectroscopy, and electrochemical frequency modulation techniques. The surfaces of the samples were characterized using SEM, EDX, and XRD techniques. The effect of temperature on the corrosion rates and inhibition process was also investigated.

\section{Experimental}

2.1. Materials Preparation. Experiments were conducted using a conventional three-electrode $200 \mathrm{~mL}$ cell assembly with the counter electrode made of platinum and saturated calomel electrode (SCE) reference electrode. API 5L-B carbon steel cut from its parent pipe was used as the test material and has the chemical composition shown in Table 1. 
TABLe 1: Chemical composition of the API 5L-B carbon steel.

\begin{tabular}{lccccc}
\hline Element & $\mathrm{C}$ & $\mathrm{Mn}$ & $P_{\max }$ & $S_{\max }$ & $\mathrm{Fe}$ \\
\hline Composition $(\mathrm{Wt} \%)$ & 0.28 & 1.2 & 0.03 & 0.03 & Balance \\
\hline
\end{tabular}

The steel was cut into coupons of dimension $1 \times$ $1 \times 0.5 \mathrm{~cm}$. the coupons were degreased with acetone, air dried and embedded into two-component epoxy resin and mounted in a glass holder. A copper wire was soldered to the rear side of the coupon as an electrical connection. The exposed surface of the electrode (of area $1 \mathrm{~cm}^{2}$ ) was wet polished with silicon carbide abrasive papers up to 1200 grit, rinsed with ethanol, and air dried $[1,2]$. This was used as the working electrode during the electrochemical test.

The test medium was $150 \mathrm{~mL} 3.5 \% \mathrm{NaCl}$ solutions saturated with carbon dioxide gas at atmospheric pressure. Before the test, the system was deaerated by flushing with $\mathrm{CO}_{2}$ gas for two hours and kept saturated with $\mathrm{CO}_{2}$ by a continuous purging of the gas [3]. The gas exit was sealed with distilled water. The temperature was maintained within $\pm 1^{\circ} \mathrm{C}$ in all experiments by placing the cell into a thermostatic water path. The $\mathrm{pH}$ was monitored with $\mathrm{PB}-10$ Sartorius $\mathrm{pH}$ meter that was carefully calibrated with two buffer solution ( $\mathrm{pH} 4$ and $\mathrm{pH} 7)$. The $\mathrm{pH}$ was $3.8 \pm 0.2$ in all experiments.

The two inhibitors, Itraconazole and Fluconazole, are triazole compounds, have the structure shown in Figure 1. Itraconazole and Fluconazole are Antifungal drugs obtained from APEX and SEDICO as trade names, Itrapex and Flucoral, respectively. Concentrations of $0.1,0.5,1,5,10,15$, 20, and $25 \mathrm{ppm}$ were used.

Potentiodynamic polarization experiments were carried out using VoltaLab-PGZ100 connected to personal computer utilizing VoltaMaster-4 software, version 7.08, while EIS and EFM were carried out using Gamry instrument G750Series Potentiostat/Galvanostat/ZRA with a Gamry framework system based on ESA400. Surface characteristics were investigated using Jeol JSM-5410 for SEM, Oxford In CA PentaFETX3 for EDX, and PANalytical X Pert Pro NC 4022 for XRD.

2.2. Experimental Procedure. The free corrosion potential (versus SCE) was followed after immersing the working electrode in the test solution until the potential stabilized within $\pm 1 \mathrm{mV}$. This was followed by EIS test, performed over the frequency range of $100 \mathrm{kHz}-100 \mathrm{mHz}$ with a signal amplitude perturbation of $5 \mathrm{mV}$.

The charge transfer resistance $\left(R_{\mathrm{ct}}\right)$ was obtained from the diameter of the semicircle in the Nyquist plot, and the inhibition efficiency determined from the relationship:

$$
\mathrm{IE} \%=\frac{R_{\mathrm{ct}}-R_{\mathrm{ct}}^{\circ}}{R_{\mathrm{ct}}} \times 100,
$$

where $R_{\mathrm{ct}}^{\circ}$ and $R_{\mathrm{ct}}$ are the uninhibited and inhibited charge transfer resistance, respectively. The characteristic frequencies $f_{\max }$ were obtained from the semicircles maxima and used to calculate the capacitance from the equation:

$$
C_{\mathrm{dL}}=\frac{1}{2 \pi f_{\max }} \frac{1}{R_{\mathrm{ct}}} .
$$

The potentiodynamic sweeps were conducted at a constant $\mathrm{pH}$ and sweep rate of $5 \mathrm{mV} \cdot \mathrm{s}^{-1}$, and the corrosion current density, $i_{\text {corr }}$, determined graphically by extrapolating the linear Tafel segment of the cathodic curves to the $E_{\text {corr }}$ (versus SCE). From the measured $i_{\text {corr }}$ values, the inhibition efficiency was calculated using the relationship:

$$
\mathrm{IE} \%=\frac{i_{\text {corr }}^{\circ}-i_{\text {corr }}}{i_{\text {corr }}^{\circ}} \times 100,
$$

where $i_{\text {corr }}^{\circ}$ and $i_{\text {corr }}$ are the uninhibited and inhibited corrosion current densities, respectively. The solution and metal coupon were changed after each sweep.

\section{Results and Discussion}

3.1. Potentiodynamic Polarization Measurements. Figures 2(a) and 2(b) show the polarization curves for API 5L-B in $\mathrm{CO}_{2}$-saturated $3.5 \% \mathrm{NaCl}$ solutions at $25^{\circ} \mathrm{C}$ and $\mathrm{pH} 3.8$, in the absence and presence of Itraconazole and Fluconazole, respectively. Polarization parameters obtained from the curves are as shown in Table 2. The introduction of the inhibitors shifted $E_{\text {corr }}$ (versus SCE) towards the negative region, and reduced $i_{\text {corr }}$. These changes are dependent on the inhibitor concentration reaching the maximum change at 15 and $20 \mathrm{ppm}$ for Itraconazole and Fluconazole, respectively.

$\mathrm{Li}$, John, and others [4-6] show that if the displacement in the corrosion potential is more than $\pm 85 \mathrm{mV}$ with respect to the blank, then the inhibitor is labeled as cathodic or anodic type; otherwise inhibitor is treated as a mixed type. In our study, the maximum displacement was 73 and $62 \mathrm{mV}$ for Itraconazole and Fluconazole, respectively. This indicates that the two inhibitors are mixed types. This means the inhibitors reduce the corrosion current without causing considerable change in the corrosion mechanism. This means also that the addition of these inhibitors to the solution reduces the anodic dissolution and retards the cathodic hydrogen evolution reaction [4].

However, the shift in the corrosion potential indicates that the inhibition for this system is probably due to the active sites blocking effect. This could be explained as the inhibitor molecules adsorb on the metal surface, form a protective film, and block the available reaction sites [6]. The formation of inhibitor film on the metal surface reduces the active surface area exposed to the corrosive medium and delays the hydrogen evolution and metal dissolution. This provides considerable protection to metal surface in the solution. The surface coverage of the inhibitor molecules on the metal surface increases with increasing the inhibitor concentration. Potentiodynamic polarization curves in Figures 2(a) and 2(b) exhibit no steep slope in the anodic range, meaning that no passive films are formed on the metal surface [7]. As per the corrosion theory the shift in the cathodic curves reveals that the corrosion process is mainly accelerated by the cathodic reactions. Accordingly, these inhibitors seem to retard hydrogen evolution reaction via blocking the active reaction sites. The inhibition efficiency of the two inhibitors found increases with increasing inhibitor concentration and reaches its highest value at 15 and $20 \mathrm{ppm}$ 


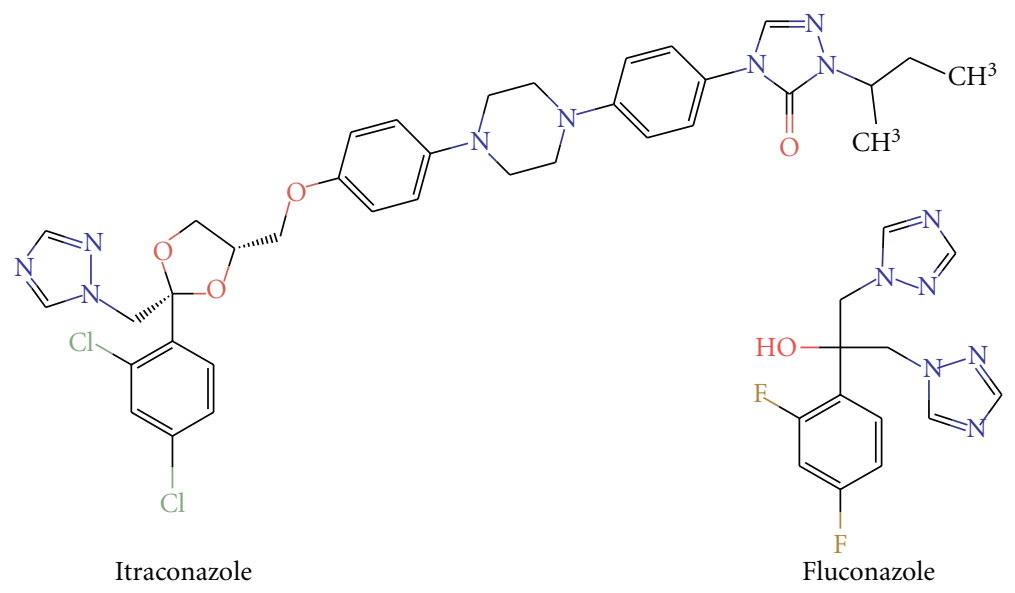

Figure 1: Molecular structures of the tested compounds.

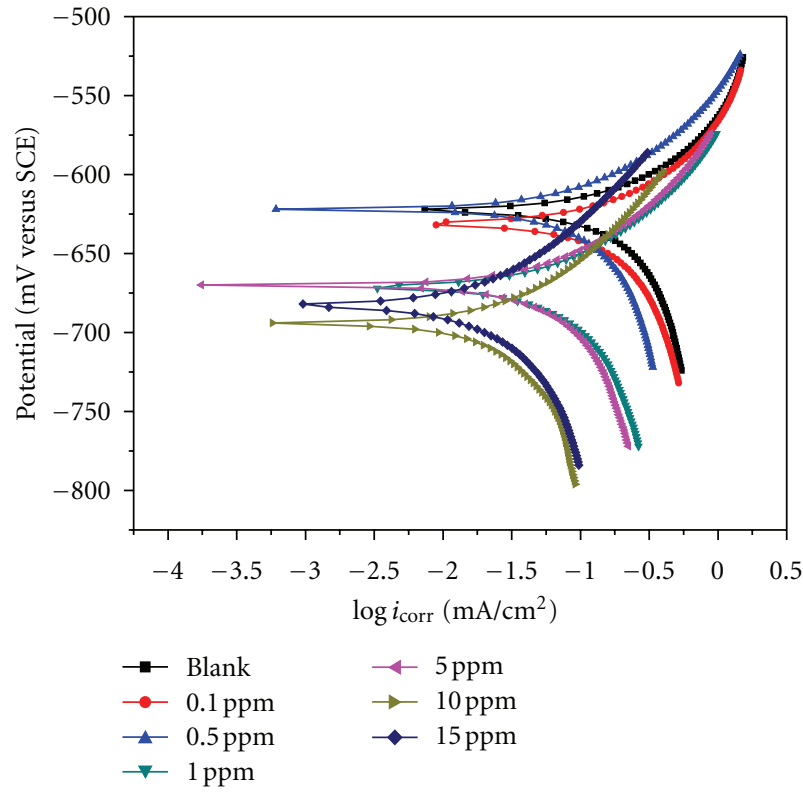

(a)

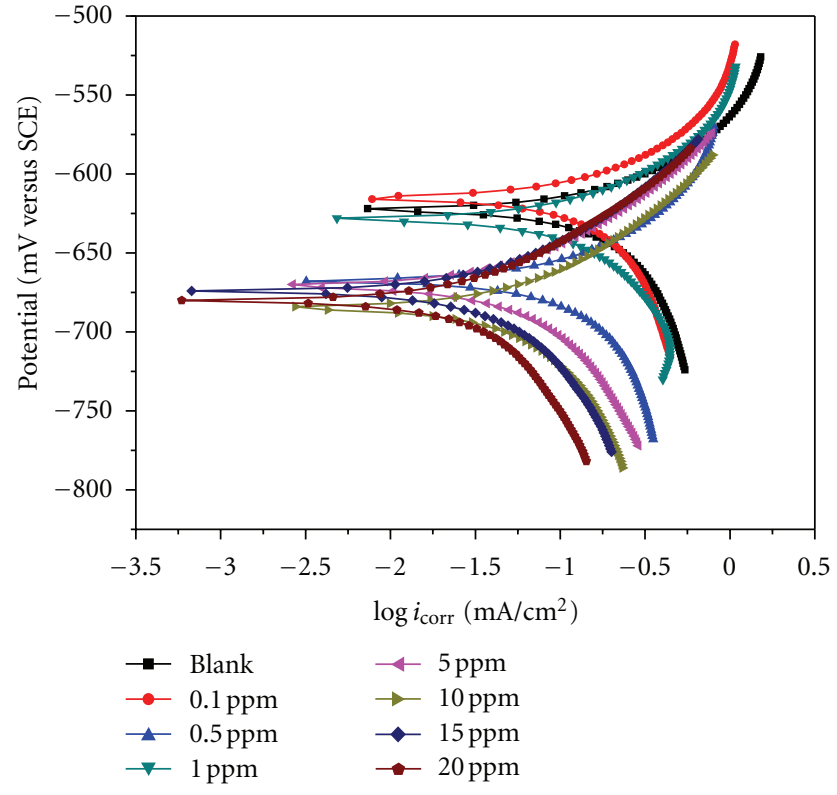

(b)

Figure 2: (a) Polarization curves in the absence and presence of Itraconazole at $25^{\circ} \mathrm{C}$. (b) Polarization curves in the absence and presence of Fluconazole at $25^{\circ} \mathrm{C}$.

for Itraconazole and Fluconazole, respectively. The increase in the inhibition efficiency with the increase in inhibitor concentration is attributed to the increased surface coverage by the inhibitor molecules as the concentration is increased [5].

3.2. Electrochemical Impedance Spectroscopy (EIS) Measurements. The Nyquist plots obtained from the EIS measurements for API 5L-B in $\mathrm{CO}_{2}$-saturated $3.5 \% \mathrm{NaCl}$ solutions at $25^{\circ} \mathrm{C}$ and $\mathrm{pH} 3.8$, in the absence and presence of Itraconazole and Fluconazole are shown in Figures 3(a) and 3(b), respectively. It is appeared from the figures that the shapes of Nyquist plots for the two inhibitors are similar. At each concentration, the shape of the Nyquist plot remained the same with one depressed semicircle in all experiments, indicating that almost no change in the corrosion mechanism occurs due to the inhibitor addition. The shape of the Nyquist plot looks comparable to that obtained by John, Joy, Prajila and others [7-9].

These diagrams indicate that the impedance spectra consist of one capacitive loop at high frequency. The introduction of the inhibitors was observed to increase the capacitive semicircles and this increase is dependent on the concentration of the inhibitors. This was ascribed to the double layer capacitance and charge transfer resistance and indicates inhibition of the corrosion process [10].

Various parameters obtained from impedance measurements as $R_{\mathrm{ct}}, C_{\mathrm{dl}}$, and $i_{\text {corr }}$ are given in Table 3 . On the introduction of the inhibitors, $R_{\mathrm{ct}}$ values increase and the 


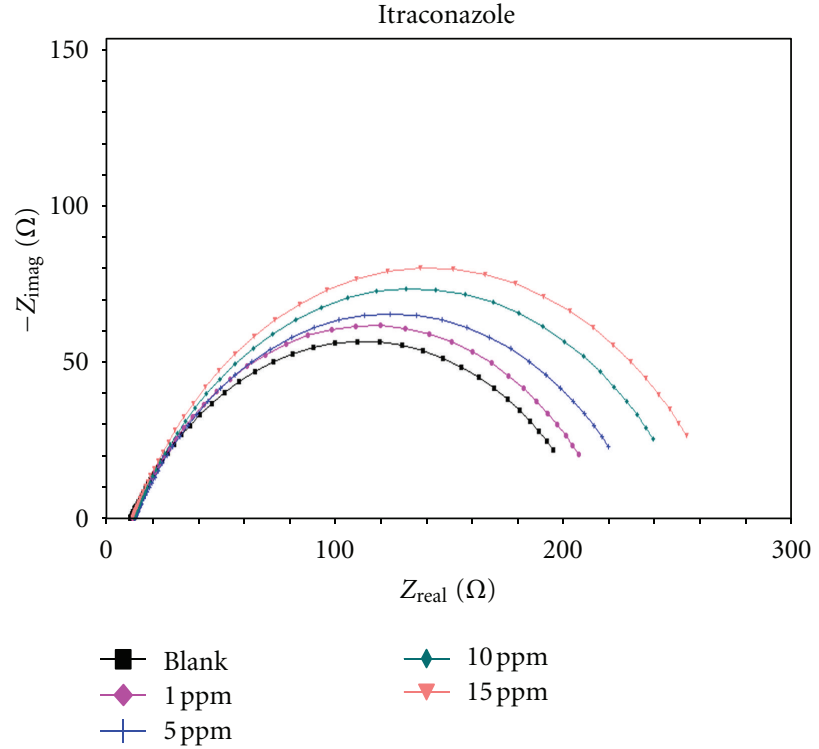

(a)

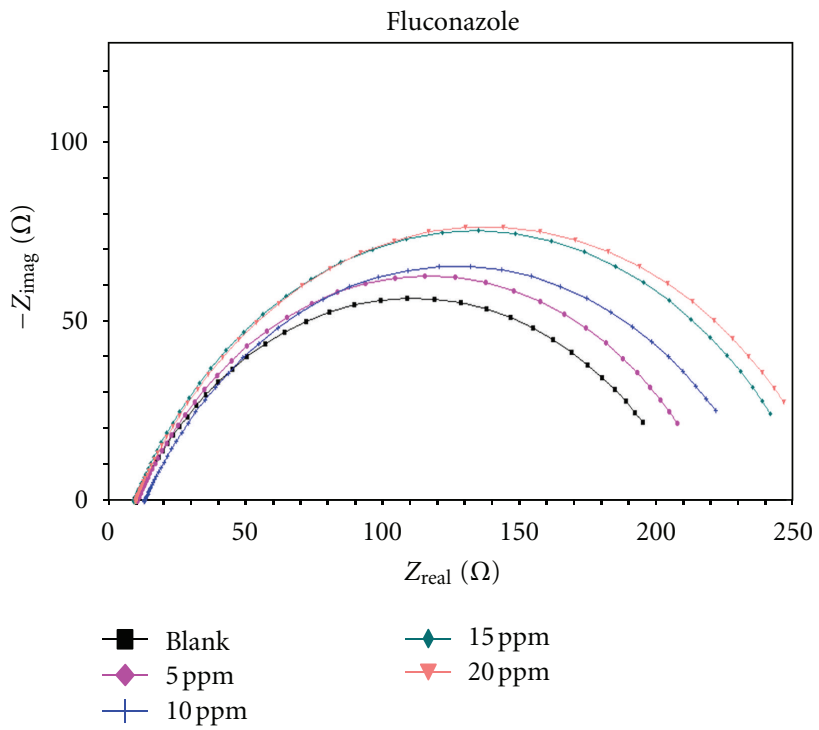

(b)

Figure 3: (a) Nyquist plot in the absence and presence of Itraconazole at $25^{\circ} \mathrm{C}$. (b) Nyquist plot in the absence and presence of Fluconazole at $25^{\circ} \mathrm{C}$.

TABLe 2: Polarization data obtained in the absence and presence of inhibitors at $25^{\circ} \mathrm{C}$.

\begin{tabular}{|c|c|c|c|c|c|c|c|c|}
\hline Comp. & $\begin{array}{c}\text { Conc., } \\
\text { ppm }\end{array}$ & $\begin{array}{c}-E_{\text {corr }} \text { versus SCE, } \\
\mathrm{mV}\end{array}$ & $\begin{array}{c}i_{\text {corr }}, \\
\mu \mathrm{A} \cdot \mathrm{cm}^{-2}\end{array}$ & $\begin{array}{c}-\beta_{c} \\
\mathrm{mV} \cdot \mathrm{dec}^{-1}\end{array}$ & $\begin{array}{c}\beta_{a} \\
\mathrm{mV} \cdot \mathrm{dec}^{-1}\end{array}$ & $\theta$ & IE, \% & $\begin{array}{c}\text { C.R, } \\
\mu \mathrm{m} \cdot \mathrm{y}^{-1}\end{array}$ \\
\hline Blank & 0 & 623 & 289 & 367 & 110 & & & 3387 \\
\hline \multirow{6}{*}{ Itraconazole } & 0.1 & 631 & 230 & 276 & 100 & 0.204 & 20.4 & 2691 \\
\hline & 0.5 & 621 & 152 & 277 & 90 & 0.474 & 47.4 & 1784 \\
\hline & 1 & 671 & 100 & 230 & 92 & 0.654 & 65.4 & 1179 \\
\hline & 5 & 670 & 90 & 255 & 91 & 0.689 & 68.9 & 1062 \\
\hline & 10 & 696 & 62 & 274 & 98 & 0.785 & 78.5 & 732 \\
\hline & 15 & 683 & 24 & 137 & 85 & 0.917 & 91.7 & 282 \\
\hline \multirow{7}{*}{ Fluconazole } & 0.1 & 615 & 221 & 330 & 110 & 0.235 & 23.5 & 2592 \\
\hline & 0.5 & 667 & 184 & 342 & 128 & 0.363 & 36.3 & 2159 \\
\hline & 1 & 628 & 144 & 147 & 80 & 0.502 & 50.2 & 1691 \\
\hline & 5 & 670 & 81 & 181 & 96 & 0.720 & 72.0 & 958 \\
\hline & 10 & 684 & 63 & 157 & 82 & 0.782 & 78.2 & 744 \\
\hline & 15 & 674 & 44 & 136 & 77 & 0.848 & 84.8 & 519 \\
\hline & 20 & 680 & 28 & 122 & 67 & 0.903 & 90.3 & 336 \\
\hline
\end{tabular}

calculated $C_{\mathrm{dl}}$ values decrease, as shown in Table 3. These changes increase with increasing inhibitor concentration.

Increasing of $R_{\mathrm{ct}}$ values could be attributed to the formation of a protective electrochemical double layer on the metal-solution interface $[10,11]$. Where $C_{\mathrm{dl}}$ values show opposite trend; that is, they decrease with increasing inhibitor concentrations; this could be due to an increase in thickness of the double layer [12]. This double layer was formed by the adsorption of the inhibitor molecules at the metal/solution interface and replaced water molecules gradually. These observations support the idea that the corrosion of API 5L-B is controlled by a charge transfer process $[9,13]$.
The inhibition efficiency, calculated from EIS results, shows the same trend as those obtained from polarization measurements. The difference in inhibition efficiency of the two methods may be due to the different surface status of the electrode in two measurements. EIS were performed at the rest potential, while in polarization measurements the electrode potential was polarized to high over potential, nonuniform current distributions, resulted from cell geometry, solution conductivity, counter and reference electrode placement, and so forth, will lead to the difference between the electrode area actually undergoing polarization and the total area [14]. 
TABLE 3: Parameters obtained from EIS in the absence and presence of inhibitors at $25^{\circ} \mathrm{C}$.

\begin{tabular}{|c|c|c|c|c|c|c|c|c|}
\hline Comp. & $\begin{array}{c}\text { Conc., } \\
\text { M }\end{array}$ & $\begin{array}{c}R_{S} \\
\Omega \mathrm{cm}^{2}\end{array}$ & $\begin{array}{c}Y \times 10^{-4} \\
\mu \Omega^{-1} \mathrm{sn}^{-2}\end{array}$ & $n$ & $\begin{array}{c}R_{\mathrm{CT}}, \\
\Omega \mathrm{cm}^{2}\end{array}$ & $\begin{array}{c}C_{\mathrm{dl}} \times 10^{-4}, \\
\mu \mathrm{Fcm}^{-2}\end{array}$ & $\theta$ & IE, \% \\
\hline Blank & 0 & 9.81 & 9.93 & 0.644 & 203.2 & 4.10 & & \\
\hline \multirow{4}{*}{ Itraconazole } & 1 & 10.85 & 8.20 & 0.674 & 210.1 & 3.50 & 0.033 & 3.3 \\
\hline & 5 & 11.92 & 8.21 & 0.669 & 224.9 & 3.56 & 0.096 & 9.6 \\
\hline & 10 & 11.38 & 7.49 & 0.684 & 245.7 & 3.43 & 0.173 & 17.3 \\
\hline & 15 & 10.80 & 6.86 & 0.698 & 260.8 & 3.26 & 0.221 & 22.1 \\
\hline \multirow{4}{*}{ Fluconazole } & 5 & 10.89 & 8.64 & 0.676 & 212.7 & 3.84 & 0.045 & 4.5 \\
\hline & 10 & 13.49 & 8.95 & 0.661 & 227.6 & 3.96 & 0.107 & 10.7 \\
\hline & 15 & 9.56 & 6.90 & 0.689 & 249.0 & 3.12 & 0.184 & 18.4 \\
\hline & 20 & 10.17 & 7.59 & 0.682 & 256.5 & 3.54 & 0.208 & 20.8 \\
\hline
\end{tabular}

TABLE 4: EFM data obtained in the absence and presence of inhibitors at $25^{\circ} \mathrm{C}$.

\begin{tabular}{|c|c|c|c|c|c|c|c|c|c|}
\hline Comp. & $\begin{array}{c}\text { Conc., } \\
\mathrm{M}\end{array}$ & $\begin{array}{c}i_{\text {corr }} \\
\mu \mathrm{A} \cdot \mathrm{cm}^{-2}\end{array}$ & $\begin{array}{c}\beta_{a} \\
\mathrm{mV} \cdot \mathrm{dec}^{-1}\end{array}$ & $\begin{array}{c}\beta_{c}, \\
\mathrm{mV} \cdot \mathrm{dec}^{-1}\end{array}$ & $\mathrm{CF}-2$ & $\mathrm{CF}-3$ & $\theta$ & IE, \% & $\begin{array}{c}\text { C.R, } \\
\mu \mathrm{my}^{-1}\end{array}$ \\
\hline Blank & 0 & 230 & 99 & 183 & 1.9 & 3.5 & 0.000 & 0.0 & 2672 \\
\hline \multirow{4}{*}{ Itraconazole } & 1 & 186 & 93 & 179 & 1.9 & 3.2 & 0.191 & 19.1 & 2164 \\
\hline & 5 & 166 & 91 & 175 & 1.9 & 3.2 & 0.278 & 27.8 & 1930 \\
\hline & 10 & 153 & 89 & 166 & 1.9 & 3.6 & 0.335 & 33.5 & 1778 \\
\hline & 15 & 143 & 81 & 149 & 1.9 & 3.8 & 0.378 & 37.8 & 1668 \\
\hline \multirow{4}{*}{ Fluconazole } & 5 & 213 & 101 & 185 & 1.9 & 3.3 & 0.074 & 7.4 & 2479 \\
\hline & 10 & 191 & 94 & 190 & 1.9 & 2.8 & 0.170 & 17.0 & 2222 \\
\hline & 15 & 182 & 94 & 180 & 1.9 & 3.4 & 0.209 & 20.9 & 2115 \\
\hline & 20 & 174 & 90 & 173 & 1.9 & 3.1 & 0.243 & 24.3 & 2026 \\
\hline
\end{tabular}

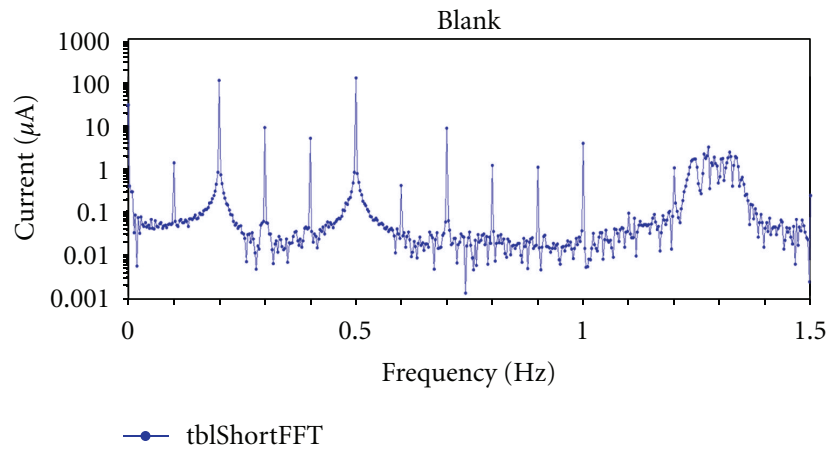

FIGURE 4: EFM spectra for the blank "in the absence inhibitors" at $25^{\circ} \mathrm{C}$.

3.3. Electrochemical Frequency Modulation (EFM) Measurements. EFM experiment was carried out assuming that the reaction is under either diffusion control or activation control and not using the passivation model since API 5L-B does not form passive films at these conditions. Results obtained from EFM measurements are intermodulation spectra shown in Figures 4, 5, and 6 for the blank, Itraconazole, and Fluconazole, respectively, and data obtained are shown in Table 4. The results show that the introduction of the inhibitors reduced $i_{\text {corr }}$ and this effect increase with increasing concentrations. The inhibition efficiency, IE (\%), calculated from (4). The causality factors in Table 4 was close to the theoretical values according to the EFM theory [15], should guarantee the validity of Tafel slopes and corrosion current densities.

3.4. Adsorption. Several adsorption isotherms were assessed and the Langmuir isotherm was found the most suitable one fit for the present case, Figure 7. The following equation was applied:

$$
\frac{C}{\theta}=\frac{1}{K_{\mathrm{ads}}}+C
$$

where $\theta$ is the surface coverage $(\theta=\mathrm{IE}(\%) / 100), C$ the inhibitor concentration, $K$ the adsorption coefficient, which represents the adsorption-desorption equilibrium constant. The obtained and $K_{\mathrm{ads}}$ values are $9.12 \times 10^{5}$ and $3.90 \times$ $10^{5}$ for Itraconazole and Fluconazole, respectively. These high values reflect the high adsorption ability of the two inhibitors on the metal surface [16-18]. The standard free energy of adsorption, $\Delta G_{\text {ads }}^{\circ}$, can be calculated from $K_{\text {ads }}$ via the following equation:

$$
K_{\mathrm{ads}}=\frac{1}{55.5} \exp \left(\frac{-\Delta G_{\mathrm{ads}}^{\circ}}{R T}\right) .
$$

The value 55.5 in the above equation is the molar concentration of water in solution in mol/L. Thermodynamic parameters for the adsorption are given in Table 5. The large 


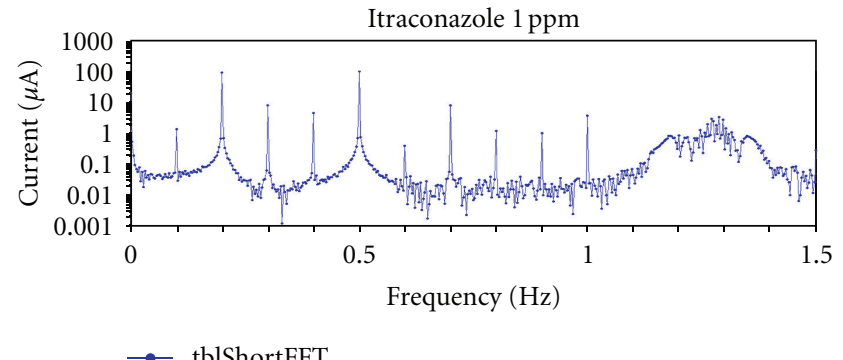

(a)

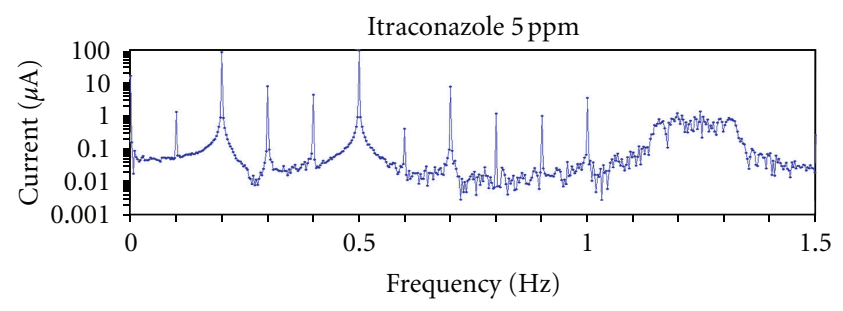

- tblShortFFT

(b)

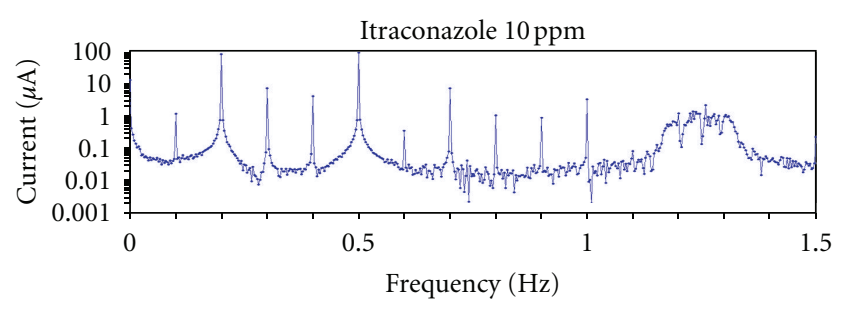

$\rightarrow$ tblShortFFT

(c)

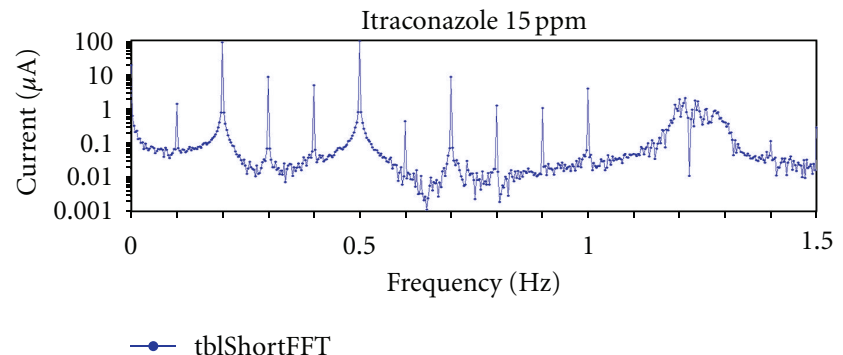

(d)

FIGURE 5: EFM Spectra in the presence of different concentrations of Itraconazole at $25^{\circ} \mathrm{C}$.

negative values of $\Delta G_{\text {ads }}^{\circ}$ in the table suggested that the adsorption process takes place spontaneously [19-21] and the adsorbed layer of the inhibitor on the metal surface is highly stable [22].

It is well known that values of $\Delta G_{\text {ads }}^{\circ}$ of the order of $20 \mathrm{~kJ} \cdot \mathrm{mol}^{-1}$ or lower indicate that the adsorption process is physisorption, that is, electrostatic interaction between charged molecules and charged metal, while those of the order of $40 \mathrm{~kJ} \cdot \mathrm{mol}^{-1}$ or higher indicate that it is chemisorption, that is, charge sharing or a transfer from the inhibitor molecules to the metal surface to form a coordinate type

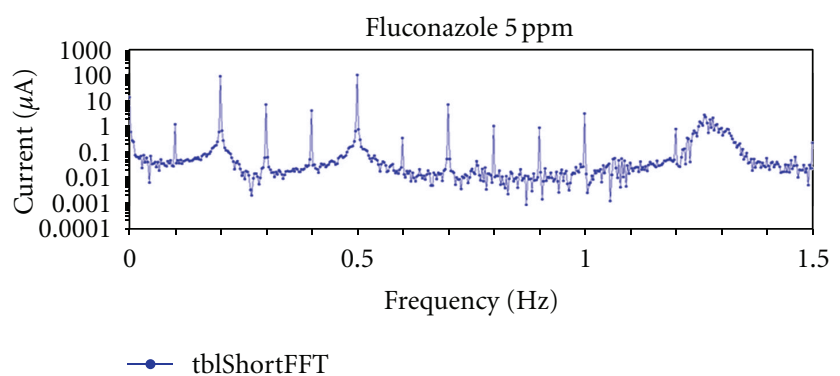

(a)

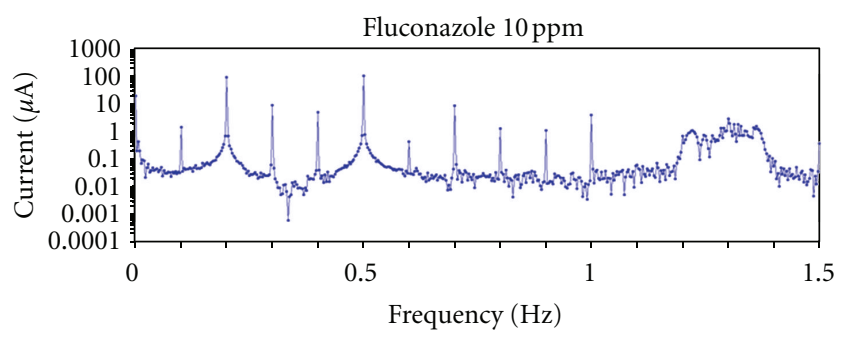

$\rightarrow$ tblShortFFT

(b)

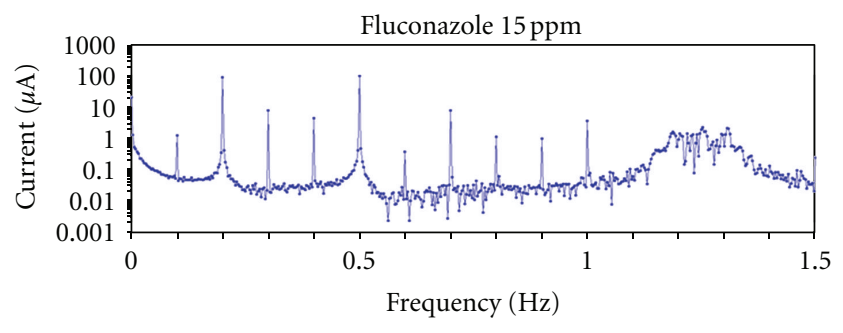

$\rightarrow$ tblShortFFT

(c)

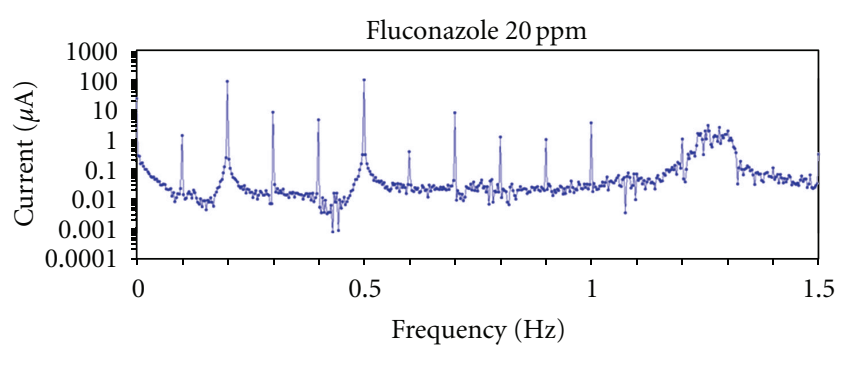

- tblShortFFT

(d)

Figure 6: EFM Spectra in the presence of different concentrations of Fluconazole at $25^{\circ} \mathrm{C}$.

bond (covalent bond) [23-27]. Accordingly, the values of $\Delta G_{\text {ads }}^{\circ}$ obtained in the present study indicate that the two inhibitors adsorbed on the metal surface by chemisorption. The same result was obtained by Tang et al. [16]. The effectiveness of Itraconazole and Fluconazole as inhibitors can be ascribed to the adsorption of their molecules on the metal surface. This adsorption could be attributed to the presence of nitrogen atoms in their molecular structures $[26,28,29]$. These atoms form iron-nitrogen coordination 


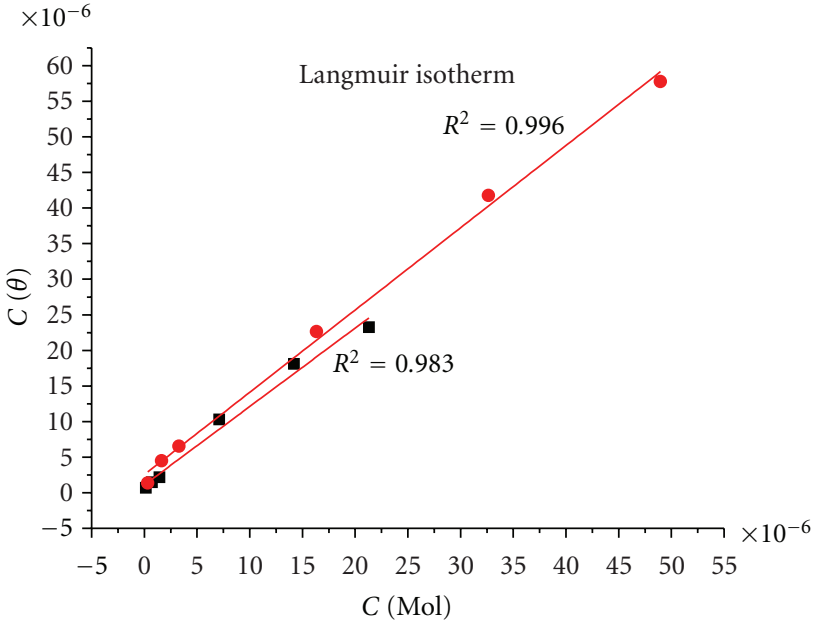

- Itraconazole

- Fluconazole

Figure 7: Langmuir adsorption isotherm for Itraconazole and Fluconazole inhibitors at $25^{\circ} \mathrm{C}$.

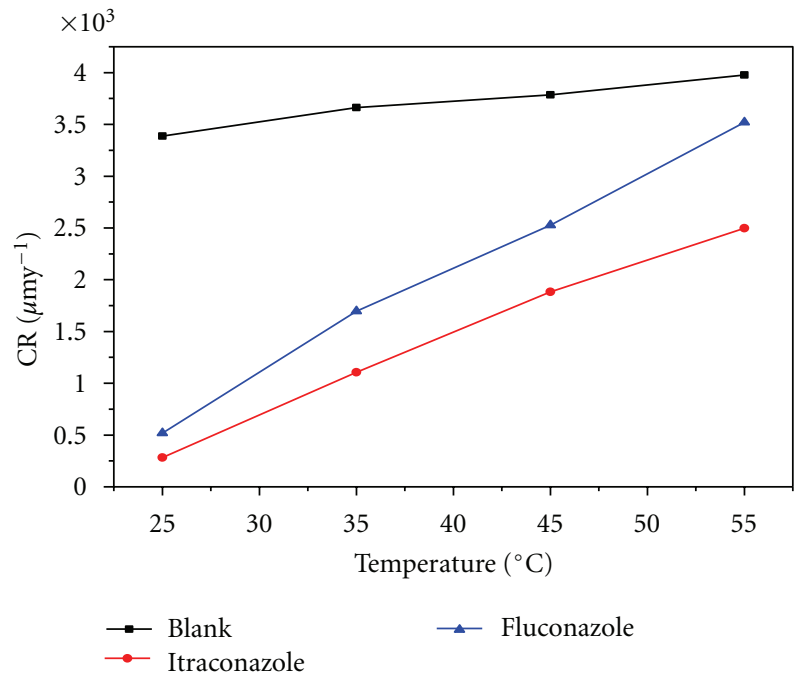

FIGURE 8: Effect of temperature on the corrosion rate in the absence and presence of inhibitors.

bonds, by a p-electron interaction between the p-electron in the head group and iron. Adsorption may also be due to the coulombic attraction (physical adsorption) [3].

3.5. Effect of Temperature. The effect of temperature on the corrosion process in the absence and presence of Itraconazole and Fluconazole is represented in Figure 8. There is a clear acceleration of both the anodic and cathodic reactions with an increase in temperature. Similar curves have been reported previously $[30,31]$. The polarization parameters are listed in Table 6 . It can be seen that $i_{\text {corr }}$ increased with temperature in the uninhibited and inhibited solutions. This is due to the acceleration of all the processes involved in

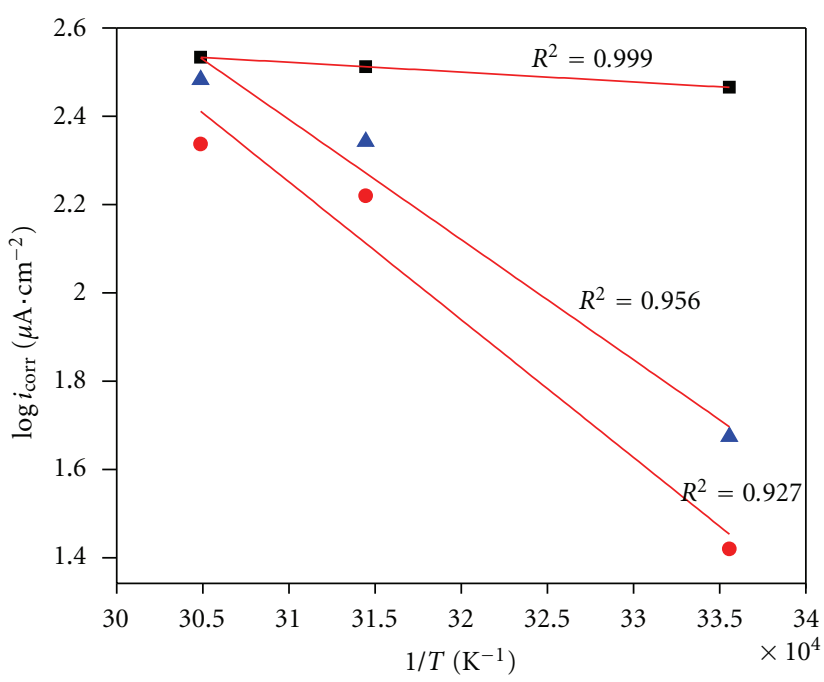

- Blank

- Itraconazole

- Fluconazole

FIGURE 9: Arrhenius plots in the absence and presence of inhibitors.

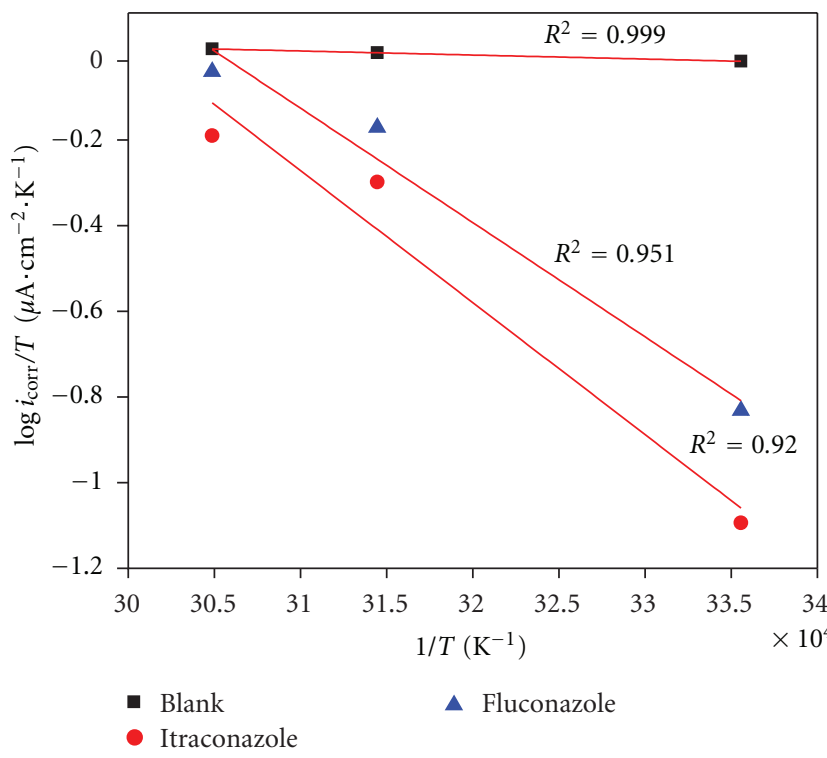

Figure 10: Variation of $\log i_{\text {corr }} / T$ versus $1 / T$ in the absence and presence of inhibitors.

corrosion: electrochemical, chemical, transport, and so forth with increase in temperature.

The apparent activation energies $\left(E_{a}^{*}\right)$ for the corrosion process in the absence and presence of inhibitors were calculated from the Arrhenius equation as follows:

$$
k=A \exp -\frac{E_{a}^{*}}{R T},
$$

where $k$ is the corrosion rate, $A$ is a constant, $R$ is the universal gas constant $\left(R=8.314 \mathrm{~J} \cdot \mathrm{mol}^{-1} \mathrm{~K}^{-1}\right)$, and $T$ is the absolute temperature.

Figure 9 presents the Arrhenius plots and $E_{a}^{*}$ values in the absence and presence of inhibitors as calculated 
TABLE 5: Thermodynamic parameters for adsorption of inhibitors at $25^{\circ} \mathrm{C}$.

\begin{tabular}{|c|c|c|c|c|c|}
\hline Comp. & $\begin{array}{c}\text { Conc., } \\
\text { ppm }\end{array}$ & $\begin{array}{c}\text { Conc. } \times 10^{6}, \\
\mathrm{M}\end{array}$ & $C / \theta \times 10^{6}$ & $K \times 10^{5}$ & $\begin{array}{c}-\Delta G^{\circ}, \\
\mathrm{kJ} \cdot \mathrm{Mol}^{-1}\end{array}$ \\
\hline \multirow{6}{*}{ Itraconazole } & 0.1 & 0.142 & 0.696 & \multirow{6}{*}{9.12} & \multirow{6}{*}{44.0} \\
\hline & 0.5 & 0.711 & 1.5 & & \\
\hline & 1 & 1.42 & 2.17 & & \\
\hline & 5 & 7.11 & 10.3 & & \\
\hline & 10 & 14.2 & 18.1 & & \\
\hline & 15 & 21.3 & 23.2 & & \\
\hline \multirow{6}{*}{ Fluconazole } & 0.1 & 0.327 & 1.39 & \multirow{6}{*}{3.90} & \multirow{6}{*}{41.9} \\
\hline & 0.5 & 1.63 & 4.49 & & \\
\hline & 1 & 3.27 & 6.51 & & \\
\hline & 5 & 16.3 & 22.7 & & \\
\hline & 10 & 32.7 & 41.8 & & \\
\hline & 15 & 49.0 & 57.8 & & \\
\hline
\end{tabular}

TABLE 6: Effect of temperature in the absence and presence of inhibitors.

\begin{tabular}{|c|c|c|c|c|c|c|c|c|}
\hline Comp. & $\begin{array}{l}\text { Temp., } \\
{ }^{\circ} \mathrm{C}\end{array}$ & $\begin{array}{c}-E_{\text {corr. }} \text { versus SCE, } \\
\mathrm{mV}\end{array}$ & $\begin{array}{c}i_{\text {corr., }} \\
\mu \mathrm{A} \mathrm{cm}^{-2}\end{array}$ & $\begin{array}{c}-\beta_{c}, \\
\mathrm{mV} \cdot \mathrm{dec}^{-1}\end{array}$ & $\begin{array}{c}\beta_{a} \\
\mathrm{mV} \cdot \mathrm{dec}^{-1}\end{array}$ & $\theta$ & IE, \% & $\begin{array}{c}\text { C.R, } \\
\mu \mathrm{m} \cdot \mathrm{y}^{-1}\end{array}$ \\
\hline \multirow{4}{*}{ Blank } & 25 & 622.7 & 289 & 367 & 110 & & & 3387 \\
\hline & 35 & 663 & 313 & 335 & 118 & & & 3663 \\
\hline & 45 & 700 & 323 & 230 & 101 & & & 3785 \\
\hline & 55 & 694 & 340 & 298 & 125 & & & 3978 \\
\hline \multirow{4}{*}{ Itraconazole } & 25 & 683 & 24 & 137 & 85 & 0.917 & 91.7 & 282 \\
\hline & 35 & 666 & 94 & 132 & 77 & 0.700 & 70.0 & 1106 \\
\hline & 45 & 689 & 161 & 277 & 112 & 0.502 & 50.2 & 1884 \\
\hline & 55 & 717 & 213 & 355 & 132 & 0.374 & 37.4 & 2498 \\
\hline \multirow{4}{*}{ Fluconazole } & 25 & 674 & 44 & 136 & 77 & 0.848 & 84.8 & 519 \\
\hline & 35 & 685 & 145 & 205 & 95 & 0.537 & 53.7 & 1697 \\
\hline & 45 & 708 & 216 & 276 & 114 & 0.331 & 33.1 & 2528 \\
\hline & 55 & 690 & 301 & 169 & 88 & 0.115 & 11.5 & 3520 \\
\hline
\end{tabular}

from the above equation are listed in Table 7. $E_{a}^{*}$ values are $4.40 \mathrm{~kJ} \cdot \mathrm{mol}^{-1}$ in the absence of the inhibitors, and $61.75 \mathrm{~kJ} \cdot \mathrm{mol}^{-1}$ and $53.84 \mathrm{~kJ} \cdot \mathrm{mol}^{-1}$ in the presence of Itraconazole and Fluconazole, respectively. The presence of inhibitors increases the activation energies of the metal dissolution by adsorption of their molecules on the metal surface, forming a double layer which is considered a barrier [18, 28, $32,33]$. The higher $E_{a}^{*}$ can be correlated with the increased thickness of the formed double layer, which increases the activation energy of the corrosion process $[4,16,23,34]$. The $E_{a}^{*}$ values in the presence of Itraconazole and Fluconazole are nearly similar, suggesting that the two inhibitors inhibit the corrosion process with similar mechanisms. It is also indicated that the whole corrosion process is controlled by surface reaction, since the activation energy ( $E_{a}^{*}$ of the corrosion process is over $20 \mathrm{~kJ} \cdot \mathrm{mol}^{-1}$ [35].

From the results, the activation energy value in the presence of Itraconazole is higher than that of Fluconazole, which support the previous results that Itraconazole has higher efficiency than Fluconazole.
The enthalpy $\left(\Delta H^{*}\right)$ and entropy $\left(\Delta S^{*}\right)$ of activation was calculated from the following equation:

$$
k=\frac{R T}{N h \exp \left(\Delta S^{*} / R\right) \exp \left(-\Delta H^{*} / R T\right)},
$$

where $h$ is Planck's constant $=6.626 \times 10^{-34} \mathrm{Js}$ and $N$ is Avogadro's number $=6.022 \times 10^{23} \mathrm{~mol}^{-1}$. Figure 10 shows the plots utilized to get the above parameters which are listed in Table 7. The increase of $\Delta H^{*}$ values in the presence of the two inhibitors may be attributed to the increased heights of the energy barriers of the corrosion process. As $\Delta H^{*}$ values are lower than $E_{a}^{*}$, the corrosion process must involve a gaseous reaction, simply the hydrogen evolution reaction, associated with a decrease in the total reaction volume. This result verified the known thermodynamic relation between $E_{a}^{*}$ and $\Delta H^{*}$ in the following equation $[32,36]$ :

$$
\Delta H^{*}=E_{a}^{*}-R T .
$$

As shown also from Table $7, \Delta S^{*}$ values are large and negative both in the absence and presence of the two inhibitors, 
TABLE 7: Activation parameters in the absence and presence of inhibitors.

\begin{tabular}{|c|c|c|c|c|c|c|}
\hline Comp. & $\begin{array}{c}\text { Conc., } \\
\text { ppm }\end{array}$ & $\begin{array}{c}\text { Temp., } \\
{ }^{\circ} \mathrm{C} \\
\end{array}$ & $\begin{array}{c}i_{\text {corr }}, \\
\mu \mathrm{A} \cdot \mathrm{cm}^{-2}\end{array}$ & $\begin{array}{c}\Delta H^{*}, \\
\mathrm{~kJ} \cdot \mathrm{mol}^{-1}\end{array}$ & $\begin{array}{c}\Delta S^{*} \\
\mathrm{~J} \cdot \mathrm{mol}^{-1} \mathrm{~K}^{-1}\end{array}$ & $\begin{array}{c}E_{a}^{*}, \\
\mathrm{~kJ} \cdot \mathrm{mol}^{-1}\end{array}$ \\
\hline & & 25 & 289 & & & \\
\hline \multirow[t]{3}{*}{ Blank } & 0 & 45 & 323 & 1.8 & -191.76 & 4.40 \\
\hline & & 55 & 340 & & & \\
\hline & & 25 & 24 & & & \\
\hline \multirow[t]{3}{*}{ Itraconazole } & 15 & 45 & 161 & 59.1 & -19.33 & 61.75 \\
\hline & & 55 & 213 & & & \\
\hline & & 25 & 44 & & & \\
\hline \multirow[t]{2}{*}{ Fluconazole } & 15 & 45 & 216 & 51.2 & -41.07 & 53.84 \\
\hline & & 55 & 301 & & & \\
\hline
\end{tabular}

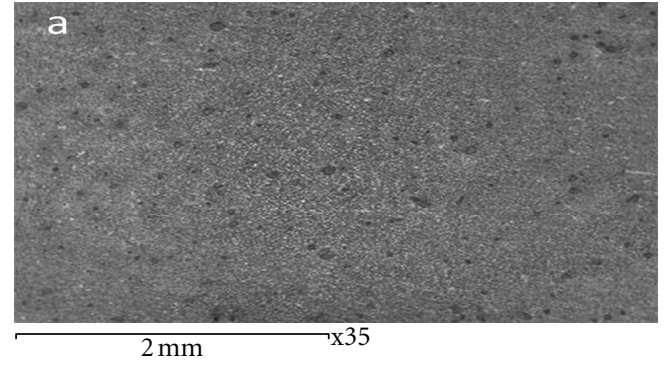

(a)

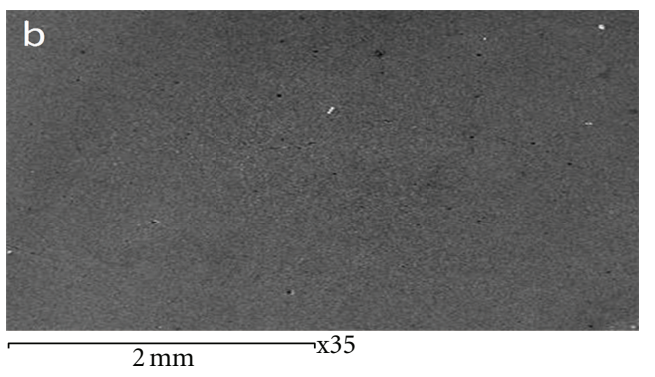

(b)

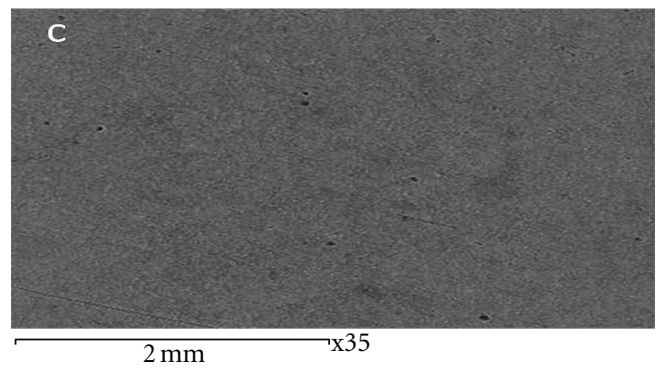

(c)

FIGURE 11: SEM images in the absence (a) in the presence of Itraconazole (b) and Fluconazole (c).

implying that the activated complex represented the rate determining step with respect to the association rather than dissociation. It means that a decrease in disorder occurred when proceeding from reactants to the activated complex

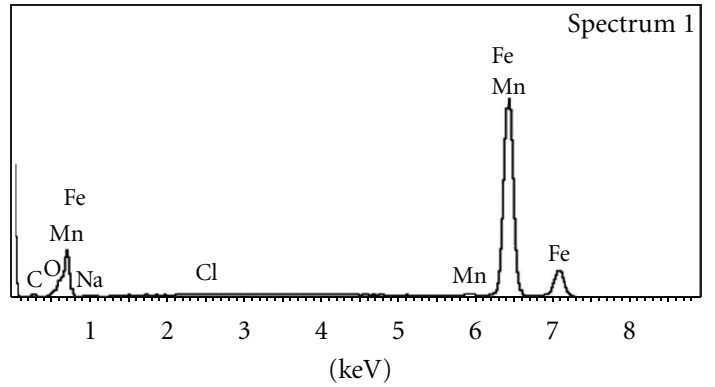

Full scale 16313 cts cursor: 8.885 ( $45 \mathrm{cts})$

(a)

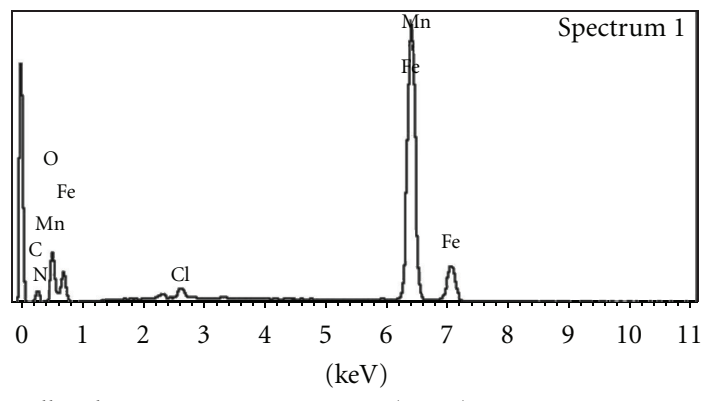

Full scale 10538 cts cursor: 11.082 (40 cts)

(b)

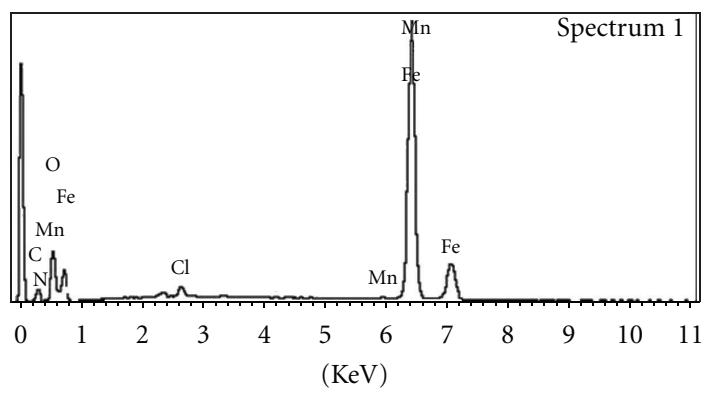

Full scale 10538 cts cursor: 11.082 (40 cts)

(c)

FIGURE 12: EDX spectra in the absence (a) and in the presence of Itraconazole (b) and Fluconazole (c). 


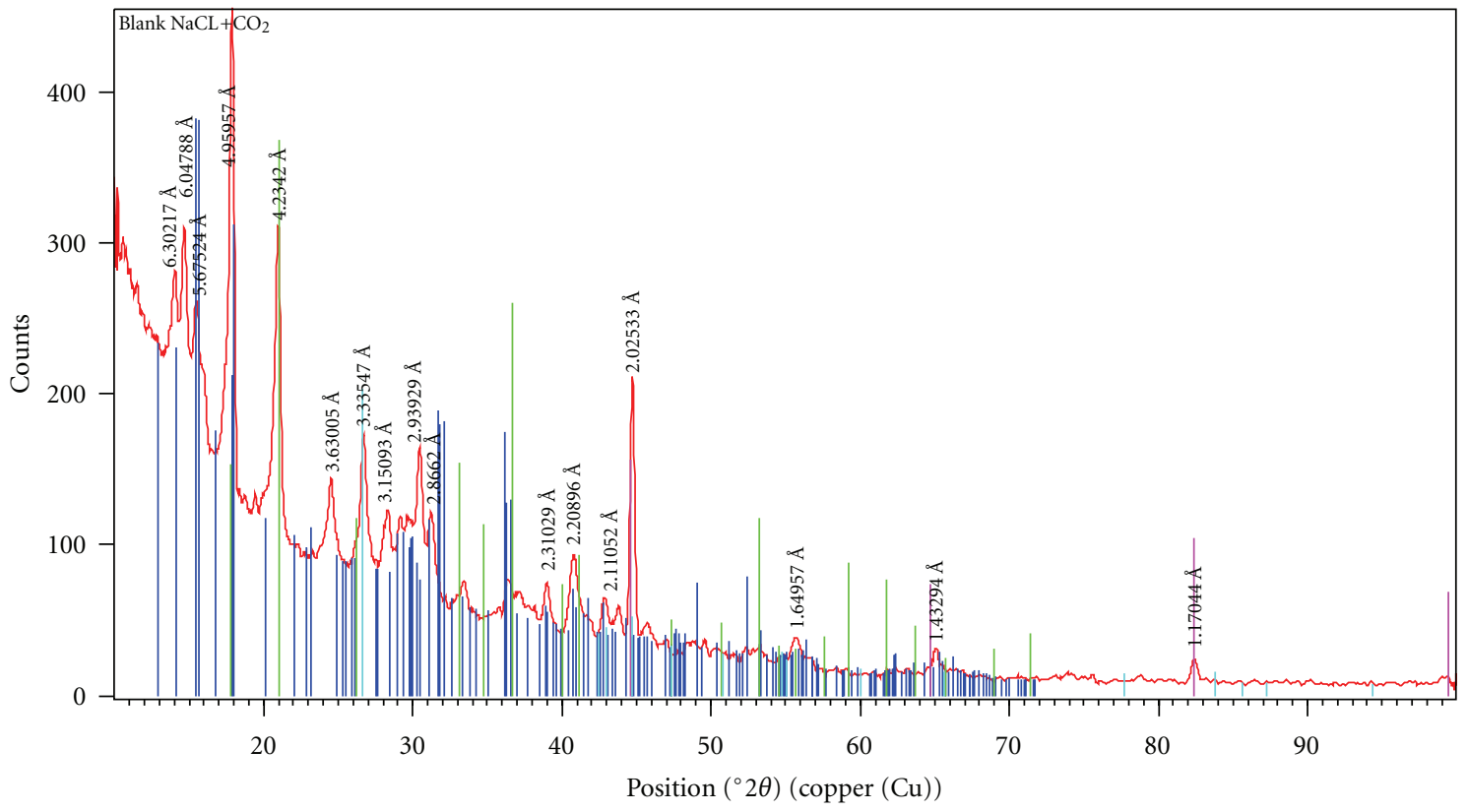

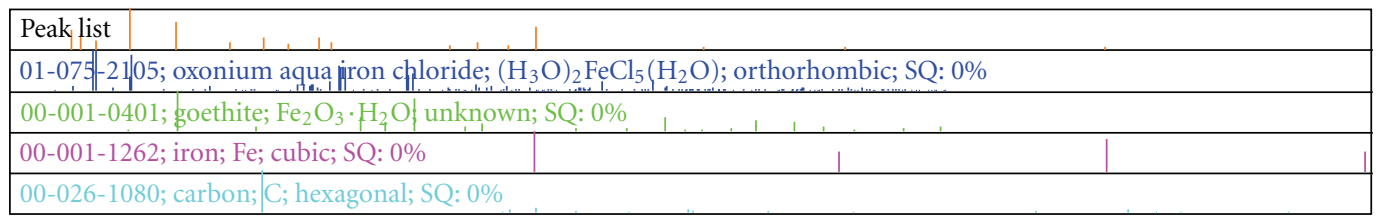

(a)

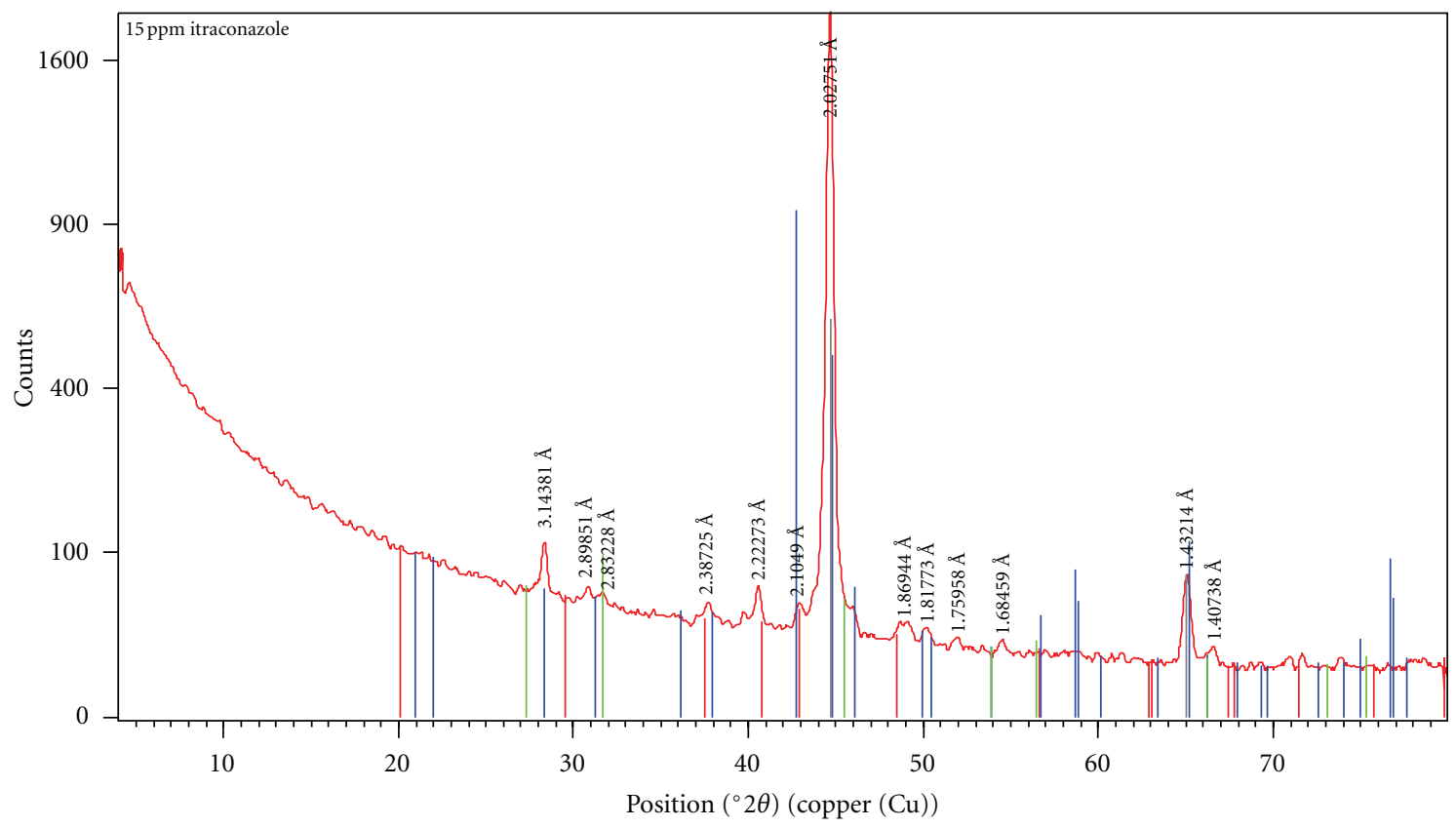

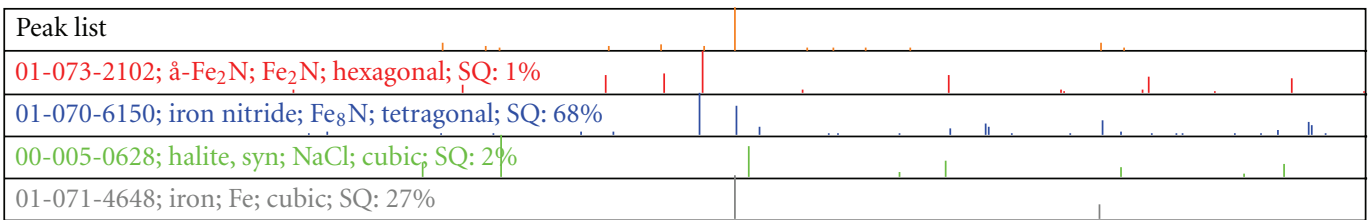

(b)

FIGURE 13: Continued. 


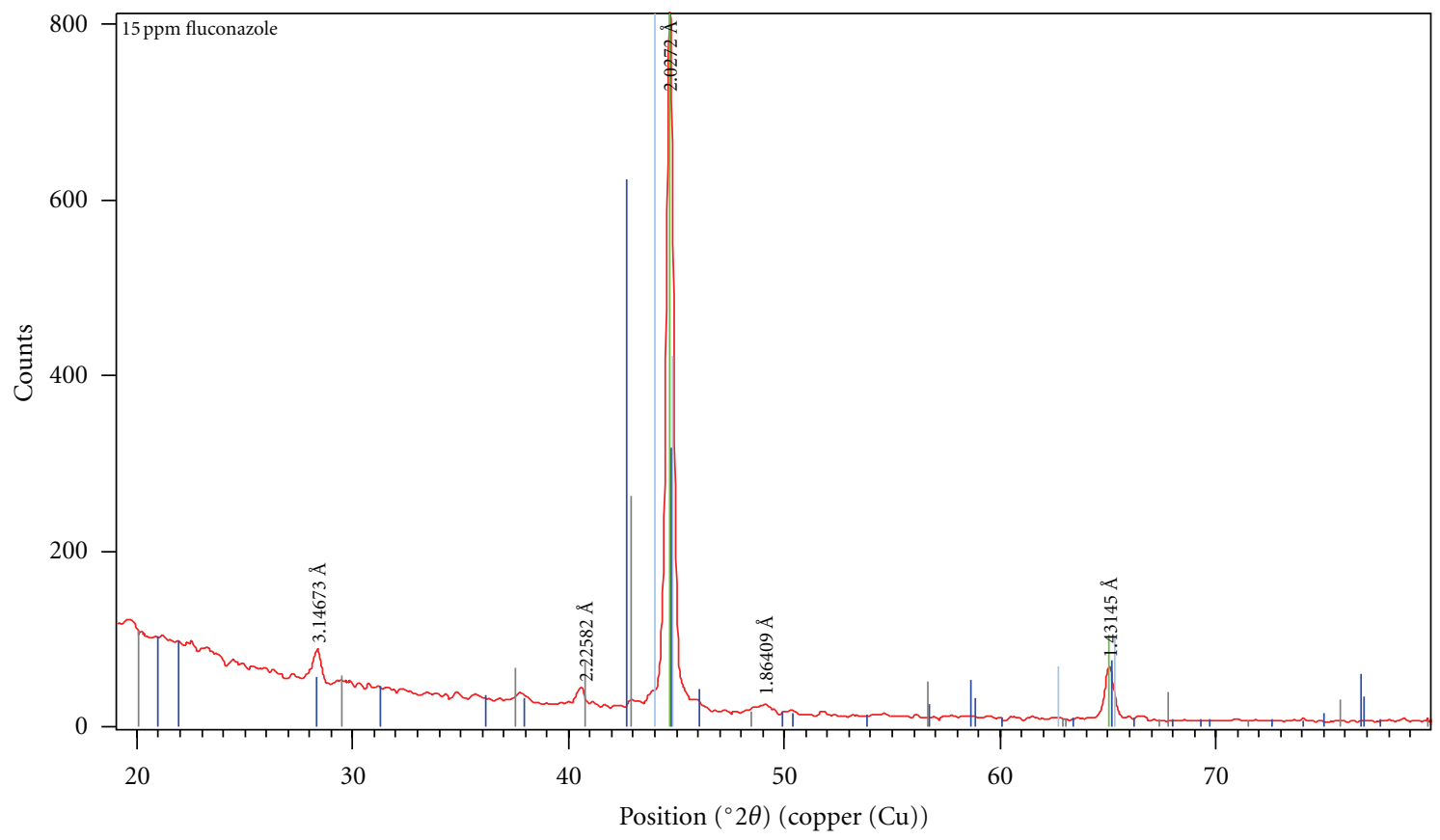

\begin{tabular}{|l|l|}
\hline Peak list & \\
\hline 01-070-6150; iron nitride; $\mathrm{Fe}_{8} \mathrm{~N}$; tetragonal; SQ; 0\% & \\
\hline 01-071-4648; iron; Fe; cubic; SQ: 0\% & , , , , \\
\hline 01-073-2102; å- $\mathrm{Fe}_{2} \mathrm{~N} ; \mathrm{Fe}_{2} \mathrm{~N}$; hexagonal; SQ; 0\% & \\
\hline
\end{tabular}

(c)

Figure 13: (a) XRD pattern for the API 5L-B specimen after immersion in $3.5 \% \mathrm{NaCl}$ solution saturated with $\mathrm{CO}_{2}$ for 3 days. (b) XRD pattern for the API 5L-B specimen after immersion in 3.5\% NaCl solution saturated with $\mathrm{CO}_{2}$ with 15 ppm Itraconazole for 3 days. (c) XRD pattern for the API 5L-B specimen after immersion in 3.5\% NaCl solution saturated with $\mathrm{CO}_{2}$ with 15 ppm Fluconazole for 3 days.

$[18,37]$. In addition, the less negative values of $\Delta S^{*}$ in the presence of inhibitors create a near-equilibrium corrosion system state [36].

As observed from the above kinetic activation parameters, Itraconazole compound exhibit higher inhibition effect than Fluconazole compound on the API 5L-B in the 3.5\% $\mathrm{NaCl}$ solution saturated with $\mathrm{CO}_{2}$.

3.6. SEM, EDX, and XRD Characterization. SEM images were taken and EDX/XRD analysis was performed in the absence and presence of $15 \mathrm{ppm}$ Itraconazole and Fluconazole for three days. As shown in SEM images (Figure 11), corrosion signs appeared on the metal surface in the uninhibited solution, Figure 11(a), and nearly disappeared in the metal surface of the inhibited solutions, Figures 11(b) and 11(c).

Figures 12(a)-12(c) show the EDX spectrum in the absence and presence of Itraconazole and Fluconazole. In the presence of inhibitors, Figures 12(b) and 12(c), EDX spectra show an additional line characteristic for the existence of $\mathrm{N}$. In addition, the intensities of $\mathrm{C}$, and $\mathrm{O}$ signals are enhanced. The appearance of the $\mathrm{N}$ signal and this enhancement in the $\mathrm{C}$ and $\mathrm{O}$ signals is due to the $\mathrm{N}, \mathrm{C}$ and $\mathrm{O}$ atoms constituting the inhibitors compounds which indicate that the inhibitor molecules have adsorbed on the metal surface.
Data obtained from the spectra are presented in Tables 8(a)8 (c). The spectra show also that Fe peaks are considerably suppressed in the presence of inhibitor which is due to the overlying inhibitor film. These results confirm those from electrochemical measurements which suggest that a surface film inhibits the metal dissolution, and hence retarded the hydrogen evolution reaction $[38,39]$.

Figures 13(a)-13(c) shows the XRD pattern in the absence and presence of Itraconazole and Fluconazole. In the absence of inhibitors, Figure 13(a), corrosion products as $\left(\mathrm{H}_{3} \mathrm{O}\right)_{2} \mathrm{FeCl}_{5}\left(\mathrm{H}_{2} \mathrm{O}\right)$ and $\mathrm{Fe}_{2} \mathrm{O}_{3} \cdot \mathrm{H}_{2} \mathrm{O}$ have been observed on the metal surface. Intensity of these compounds is much higher on the metal surface as indicated by the related peaks. In the presence of inhibitors, Figures 13(b) and 13(c), iron nitrides as $\mathrm{Fe}_{2} \mathrm{~N}$ and $\mathrm{Fe}_{8} \mathrm{~N}$ have been observed on the metal surfaces which represent the protective films formed due to interaction of iron with the inhibitor molecules. Intensity of these compounds is much higher on the metal surface as indicated by the related peaks which indicate that these compounds have covered the metal surface and protected iron from the corrosive media. Also, narrow peaks of these compounds indicate that the formed films have crystallized characteristics; this led to increase in the level of protection which is confirmed by the absence of corrosion products 
TABle 8: (a) Data obtained from EDX in the absence of inhibitors. (b) Data obtained from EDX in the presence of Itraconazole. (c) Data obtained from EDX in the presence of Fluconazole.

(a)

\begin{tabular}{lccccc}
\hline Element & App & Intensity & Weight\% & Weight\% & Sigma \\
Conc. & Corrn. & 0.3861 & 7.41 & 0.66 & Atomic\% \\
C K & 23.46 & 0.9789 & 3.27 & 0.31 & 8.39 \\
O K & 26.22 & 0.2435 & 0.47 & 0.21 & 0.84 \\
Na K & 0.94 & 0.6974 & 0.17 & 0.06 & 0.19 \\
Cl K & 0.96 & 0.9508 & 0.52 & 0.09 & 0.39 \\
Mn K & 4.03 & 0.9756 & 88.17 & 0.72 & 64.85 \\
Fe K & 705.48 & & 100.00 & & \\
\hline Totals & & & &
\end{tabular}

(b)

\begin{tabular}{lccccc}
\hline Element & App & Intensity & Weight $\%$ & Weight\% & Sigma \\
Conc. & Corrn. & 0.4193 & 13.66 & 0.65 & Atomic\% \\
\hline C K & 59.48 & 0.1868 & 0.56 & 0.63 & 1.12 \\
N K & 1.09 & 0.8666 & 19.41 & 0.42 & 33.80 \\
O K & 174.71 & 0.7235 & 1.06 & 0.06 & 0.83 \\
Cl K & 7.93 & 0.9092 & 0.26 & 0.07 & 0.13 \\
Mn K & 2.50 & 0.9303 & 100.00 & 0.71 & 32.44 \\
Fe K & 628.41 & & & & \\
\hline Totals & & &
\end{tabular}

(c)

\begin{tabular}{|c|c|c|c|c|c|}
\hline Element & $\begin{array}{c}\text { App } \\
\text { Conc. }\end{array}$ & $\begin{array}{c}\text { Intensity } \\
\text { Corrn. }\end{array}$ & Weight\% & $\begin{array}{c}\text { Weight } \% \\
\text { Sigma } \\
\end{array}$ & Atomic $\%$ \\
\hline $\mathrm{CK}$ & 49.25 & 0.3988 & 12.85 & 0.68 & 34.16 \\
\hline N K & 0.80 & 0.1860 & 0.45 & 0.61 & 1.02 \\
\hline $\mathrm{OK}$ & 69.13 & 0.8586 & 8.38 & 0.35 & 16.72 \\
\hline $\mathrm{Na} \mathrm{K}$ & 10.04 & 0.2682 & 3.89 & 0.23 & 5.41 \\
\hline $\mathrm{Cl} \mathrm{K}$ & 3.09 & 0.7080 & 0.45 & 0.06 & 0.41 \\
\hline Mn K & 2.92 & 0.9260 & 0.33 & 0.07 & 0.19 \\
\hline Fe K & 671.46 & 0.9486 & 73.65 & 0.80 & 42.10 \\
\hline Totals & & & 100.00 & & \\
\hline
\end{tabular}

in the presence of iron nitrides [40]. Nitride coatings have been used in numerous applications to increase the hardness and improve the wear and corrosion resistance of structural materials, as well as in various high-tech areas, where their functional rather than mechanical properties are of prime importance $[41,42]$.

\section{Mechanism of Inhibition}

Two modes of adsorption are considered on the metal surface in acid media. In the first mode, the neutral molecules may be adsorbed on the surface of carbon steel through the chemisorption mechanism, involving the displacement of water molecules from the carbon steel surface and sharing the electrons between the hetero-atoms and iron. The inhibitor molecules can also adsorb on the steel surface on the basis of donor-acceptor interactions between $\pi$ electrons of aromatic ring and vacant d-orbitals of surface iron atoms. In the second mode, since it is well known that the steel surface bears positive charge in acid solution [43, $44]$, so it is difficult for the protonated molecules to approach the positively charged steel surface due to the electrostatic repulsion. Since chloride ions have a smaller degree of hydration, thus and they could bring excess negative charges in the vicinity of the interface and favor more adsorption of the positively charged inhibitor molecules, the protonated investigated compounds adsorb through electrostatic interactions between the positively charged molecules and negatively charged metal surface. Thus, there is a synergism between adsorbed $\mathrm{Cl}^{-}$ions and protonated investigated compounds. Thus we can conclude that inhibition of API 5L$\mathrm{B}$ corrosion in $\mathrm{CO}_{2}$-saturated $3.5 \% \mathrm{NaCl}$ solutions is mainly due to electrostatic interaction. The decrease in inhibition 
efficiency with rise in temperature supports electrostatic interaction.

The higher inhibition of Itraconazole in comparison with Fluconazole may be attributed to the larger number of nitrogen atoms in the molecular structure of the former. In addition, acid anions such as $\mathrm{Cl}^{-}$and $\mathrm{F}^{-}$may be specifically adsorbed on the metal surface, donating an excess negative charge to the metal surface. In this way, potential of zero charge (PZC) becomes less negative which promotes the adsorption of inhibitors in cationic form. These observations were addressed by others $[28,32,45]$.

\section{Conclusion}

Itraconazole and Fluconazole compounds are good inhibitors for API 5L-B in $3.5 \% \mathrm{NaCl}$ solution saturated with $\mathrm{CO}_{2}$. The two compounds classified as mixed type as their molecules adsorbed on the metal surface, forming protective film, and blocking the available reaction sites exposed to the corrosive medium. At $25^{\circ} \mathrm{C}$, corrosion rates decrease by increasing inhibitor concentrations to reach the lowest values at 15 and $20 \mathrm{ppm}$ for Itraconazole and Fluconazole, respectively. Inhibition efficiency reached to $92 \%$ and $90 \%$ for the two inhibitors at these concentrations. At higher temperatures, corrosion rates increased in the absence and presence of the two inhibitors.

The two inhibitors adsorbed on the steel surface according to Langmuir isotherm. $\Delta G_{\text {ads }}^{\circ}$ values are large and negative which means that the process is spontaneous. $\Delta G_{\mathrm{ads}}^{\circ}$ values are higher than $40 \mathrm{~kJ} \cdot \mathrm{mol}^{-1}$ which means that the adsorption is chemisorption.

$E_{a}^{*}$ values increased by the addition of the two compounds, so that the activation energy of the metal dissolution increased due to the adsorption of the organic molecules on the metal surface, forming a double layer which is considered a barrier for corrosion. $\Delta H^{*}$ values are lower than $E_{a}^{*}$ indicating that the corrosion process must involve a gaseous reaction, simply the hydrogen evolution reaction, associated with a decrease in the total reaction volume. $\Delta S^{*}$ values are large and negative in the absence and presence of the two inhibitors, implying that the activated complex represented the rate determining step with respect to the association rather than dissociation. It means that a decrease in disorder occurred when proceeding from reactants to the activated complex.

SEM images show corrosion as scattered pits on the metal surface immersed in the test solution without inhibitors, while those of the specimens after adding $15 \mathrm{ppm}$ of inhibitors show clean surfaces and disappear of most corrosion signs. EDX spectra for specimens inserted in the inhibited solutions showed an additional line characteristic for the existence of $\mathrm{N}$. Also, intensities of $\mathrm{C}$ and $\mathrm{O}$ signals are enhanced. These results confirm that a carbonaceous material containing these atoms has covered the metal surface. This layer is undoubtedly due to the inhibitor. Also, Fe peaks in case of inhibited solutions are suppressed due to the overlying inhibitor film. These results support that a surface film has formed and reduced the metal dissolution. XRD patterns for specimen surface in case of inhabited solutions show the formation of iron nitrides $\left(\mathrm{Fe}_{2} \mathrm{~N}\right.$ and $\left.\mathrm{Fe}_{8} \mathrm{~N}\right)$ on the metal surface which represent the protective film formed due to interaction of iron with the inhibitor molecules.

All above results show that Itraconazole and Fluconazole compounds are good inhibitors for API $5 \mathrm{~L}-\mathrm{B}$ in $3.5 \% \mathrm{NaCl}$ solution saturated with $\mathrm{CO}_{2}$. Also, all results show that Itraconazole compound has higher inhibition efficiency than Fluconazole despite its lower cost.

\section{Conflict of Interests}

None of the authors of this paper has any direct financial relation with the commercial identity mentioned in the paper that might lead to a conflict of interests for any of the authors.

\section{References}

[1] P. C. Okafor, X. Liu, and Y. G. Zheng, "Corrosion inhibition of mild steel by ethylamino imidazoline derivative in $\mathrm{CO}_{2}$ saturated solution," Corrosion Science, vol. 51, no. 4, pp. 761$768,2009$.

[2] M. Heydari and M. Javidi, "Corrosion inhibition and adsorption behaviour of an amido-imidazoline derivative on API 5L $\mathrm{X} 52$ steel in $\mathrm{CO}_{2}$-saturated solution and synergistic effect of iodide ions," Corrosion Science, vol. 61, pp. 148-155, 2012.

[3] X. Liu, P. C. Okafor, and Y. G. Zheng, "The inhibition of $\mathrm{CO}_{2}$ corrosion of N80 mild steel in single liquid phase and liquid/particle two-phase flow by aminoethyl imidazoline derivatives," Corrosion Science, vol. 51, no. 4, pp. 744-751, 2009.

[4] B. D. Mert, M. Erman Mert, G. Kardaş, and B. Yazıc, "Experimental and theoretical investigation of 3-amino-1, 2, 4triazole-5-thiol as a corrosion inhibitor for carbon steel in $\mathrm{HCl}$ medium," Corrosion Science, vol. 53, no. 12, pp. 4265-4272, 2011.

[5] B. S. Sanatkumar, J. Nayak, and A. N. Shetty, "Influence of 2(4-chlorophenyl)-2-oxoethyl benzoate on the hydrogen evolution and corrosion inhibition of $18 \mathrm{Ni} 250$ grade weld aged maraging steel in $1.0 \mathrm{M}$ sulfuric acid medium," International Journal of Hydrogen Energy, vol. 37, pp. 9431-9442, 2012.

[6] W. H. Li, Q. He, S. T. Zhang, C. L. Pei, and B. R. Hou, "Some new triazole derivatives as inhibitors for mild steel corrosion in acidic medium," Journal of Applied Electrochemistry, vol. 38, no. 3, pp. 289-295, 2008.

[7] S. John, K. M. Ali, and A. Joseph, "Electrochemical, surface analytical and quantum chemical studies on Schiff bases of 4amino-4H-1,2,4-triazole-3,5-dimethanol (ATD) in corrosion protection of aluminium in $1 \mathrm{~N}^{-\mathrm{HNO}_{3}}$, Journal of Materials Science, vol. 34, no. 6, pp. 1245-1256, 2011.

[8] S. John, J. Joy, M. Prajila, and A. Joseph, "Electrochemical, quantum chemical, and molecular dynamics studies on the interaction of 4-amino-4H,3,5-di(methoxy)-1,2,4-triazole (ATD), BATD, and DBATD on copper metal in $1 \mathrm{~N} \mathrm{H}_{2} \mathrm{SO}_{4}$," Materials and Corrosion, vol. 62, no. 11, 2011.

[9] F. A. Ansari and M. A. Quraishi, "Inhibitive effect of some gemini surfactants as corrosion inhibitors for mild steel in acetic acid media," Arabian Journal for Science and Engineering, vol. 36, no. 1, pp. 11-20, 2011.

[10] F. Bentiss, M. Traisnel, and M. Lagrenee, "The substituted 1,3,4-oxadiazoles: a new class of corrosion inhibitors of mild steel in acidic media," Corrosion Science, vol. 42, no. 1, pp. 127146, 2000. 
[11] S. Muralidharan, K. L. N. Phani, S. Pitchumani, S. Ravichandran, and S. V. K. Iyer, "Polyamino-benzoquinone polymers: a new class of corrosion inhibitors for mild steel," Journal of the Electrochemical Society, vol. 142, no. 5, pp. 1478-1483, 1995.

[12] M. G. Hosseini, M. Ehteshamzadeh, and T. Shahrabi, "Protection of mild steel corrosion with Schiff bases in $0.5 \mathrm{M} \mathrm{H}_{2} \mathrm{SO}_{4}$ solution," Electrochimica Acta, vol. 52, no. 11, pp. 3680-3685, 2007.

[13] H. Wang, X. Wang, H. Wang, L. Wang, and A. Liu, "DFT study of new bipyrazole derivatives and their potential activity as corrosion inhibitors," Journal of Molecular Modeling, vol. 13, no. 1, pp. 147-153, 2007.

[14] Gamry Echem Analyst Manual, 2003.

[15] R. W. Bosch, "Electrochemical frequency modulation: a new electrochemical technique for online corrosion monitoring," Corrosion, vol. 57, no. 1, pp. 60-70, 2001.

[16] Y. M. Tang, Y. Chen, W. Z. Yang, Y. Liu, X. S. Yin, and J. T. Wang, "Electrochemical and theoretical studies of thienylsubstituted amino triazoles on corrosion inhibition of copper in $0.5 \mathrm{M} \mathrm{H}_{2} \mathrm{SO}_{4}$," Journal of Applied Electrochemistry, vol. 38, no. 11 , pp. 1553-1559, 2008.

[17] M. A. Migahed, "Electrochemical investigation of the corrosion behaviour of mild steel in $2 \mathrm{M} \mathrm{HCl}$ solution in presence of 1-dodecyl-4-methoxy pyridinium bromide," Materials Chemistry and Physics, vol. 93, no. 1, pp. 48-53, 2005.

[18] A. S. Fouda, G. Y. Elewady, and M. N. El-Haddad, "Corrosion inhibition of carbon steel in acidic solution using some azodyes," Canadian Journal on Scientific and Industrial Research, vol. 2, no. 1, 2011.

[19] H. Amar, A. Tounsi, A. Makayssi, A. Derja, J. Benzakour, and A. Outzourhit, "Corrosion inhibition of Armco iron by 2-mercaptobenzimidazole in sodium chloride 3\% media," Corrosion Science, vol. 49, no. 7, pp. 2936-2945, 2007.

[20] G. Avci, "Corrosion inhibition of indole-3-acetic acid on mild steel in $0.5 \mathrm{M} \mathrm{HCl}$," Colloids and Surfaces A, vol. 317, no. 1-3, pp. 730-736, 2008.

[21] M. Abdallah, "Rhodanine azosulpha drugs as corrosion inhibitors for corrosion of 304 stainless steel in hydrochloric acid solution," Corrosion Science, vol. 44, no. 4, pp. 717-728, 2002.

[22] M. Lebrini, M. Lagrenée, M. Traisnel, L. Gengembre, H. Vezin, and F. Bentiss, "Enhanced corrosion resistance of mild steel in normal sulfuric acid medium by 2,5-bis(n-thienyl)1,3,4-thiadiazoles: electrochemical, X-ray photoelectron spectroscopy and theoretical studies," Applied Surface Science, vol. 253, no. 23, pp. 9267-9276, 2007.

[23] G. Moretti, F. Guidi, and G. Grion, "Tryptamine as a green iron corrosion inhibitor in $0.5 \mathrm{M}$ deaerated sulphuric acid," Corrosion Science, vol. 46, no. 2, pp. 387-403, 2004.

[24] F. M. Donahue and K. Nobe, "Theory of organic corrosion inhibitors adsorption and linear free energy relationships," Journal of The Electrochemical Society, vol. 112, no. 9, pp. 886891, 1965.

[25] E. Kamis, F. Belluci, R. M. Latanision, and E. S. H. El-Ashry, "Acid corrosion inhibition of nickel by 2-(triphenosphoranylidene) succinic anhydride," Corrosion, vol. 47, no. 9, pp. 677$686,1991$.

[26] O. Benali, L. Larabi, M. Traisnel, L. Gengembre, and Y. Harek, "Electrochemical, theoretical and XPS studies of 2-mercapto1-methylimidazole adsorption on carbon steel in $1 \mathrm{M} \mathrm{HClO}_{4}$," Applied Surface Science, vol. 253, no. 14, pp. 6130-6139, 2007.

[27] R. Solmaz, G. Kardaş, M. Çulha, B. Yazici, and M. Erbil, "Investigation of adsorption and inhibitive effect of 2-mercaptothiazoline on corrosion of mild steel in hydrochloric acid media," Electrochimica Acta, vol. 53, no. 20, pp. 5941-5952, 2008.

[28] J. Aljourani, K. Raeissi, and M. A. Golozar, "Benzimidazole and its derivatives as corrosion inhibitors for mild steel in $1 \mathrm{M} \mathrm{HCl}$ solution," Corrosion Science, vol. 51, no. 8, pp. 1836$1843,2009$.

[29] F. Bentiss, M. Lebrini, and M. Lagrenée, "Thermodynamic characterization of metal dissolution and inhibitor adsorption processes in mild steel/2,5-bis(n-thienyl)-1,3,4-thiadiazoles/ hydrochloric acid system," Corrosion Science, vol. 47, no. 12, pp. 2915-2931, 2005.

[30] A. Y. Musa, A. B. Mohamad, A. A. H. Kadhum, M. S. Takriff, and L. T. Tien, "Synergistic effect of potassium iodide with phthalazone on the corrosion inhibition of mild steel in 1.0 M HCl," Corrosion Science, vol. 53, no. 11, pp. 3672-3677, 2011.

[31] S. Ghareba and S. Omanovic, "The effect of electrolyte flow on the performance of 12-aminododecanoic acid as a carbon steel corrosion inhibitor in $\mathrm{CO}_{2}$-saturated hydrochloric acid," Corrosion Science, vol. 53, no. 11, pp. 3805-3812, 2011.

[32] E. A. Noor and A. H. Al-Moubaraki, "Thermodynamic study of metal corrosion and inhibitor adsorption processes in mild steel/1-methyl-4[4'(-X)-styryl pyridinium iodides/ hydrochloric acid systems," Materials Chemistry and Physics, vol. 110, no. 1, pp. 145-154, 2008.

[33] L. Larabi, Y. Harek, O. Benali, and S. Ghalem, "Hydrazide derivatives as corrosion inhibitors for mild steel in $1 \mathrm{M} \mathrm{HCl,"}$ Progress in Organic Coatings, vol. 54, no. 3, pp. 256-262, 2005.

[34] Y. P. Khodyrev, E. S. Batyeva, E. K. Badeeva, E. V. Platova, L. Tiwari, and O. G. Sinyashin, "The inhibition action of ammonium salts of O,O-dialkyldithiophosphoric acid on carbon dioxide corrosion of mild steel," Corrosion Science, vol. 53, no. 3, pp. 976-983, 2011.

[35] K. K. Al-Neami, A. K. Mohamed, I. M. Kenawy, and A. S. Fouda, "Inhibition of the corrosion of iron by oxygen and nitrogen containing compounds," Monatshefte für Chemie Chemical Monthly, vol. 126, no. 4, pp. 369-376, 1995.

[36] Y. A. Elewady, A. S. Fouda, and H. K. Zeid, "Corrosion behavior of some petroleum equipment in acidic media," Physical Chemistry, Mansoura University. In press.

[37] G. E. Badr, "The role of some thiosemicarbazide derivatives as corrosion inhibitors for C-steel in acidic media," Corrosion Science, vol. 51, no. 11, pp. 2529-2536, 2009.

[38] S. S. A. Rehim, O. A. Hazzazi, M. A. Amin, and K. F. Khaled, "On the corrosion inhibition of low carbon steel in concentrated sulphuric acid solutions-part I: chemical and electrochemical (AC and DC) studies," Corrosion Science, vol. 50, no. 8, pp. 2258-2271, 2008.

[39] L. Fragoza-Mar, O. Olivares-Xometl, M. A. DomnguezAguilar, E. A. Flores, P. Arellanes-Lozada, and F. Jiménez-Cruz, "Corrosion inhibitor activity of 1, 3-diketone malonates for mild steel in aqueous hydrochloric acid solution," Corrosion Science, vol. 61, pp. 171-184, 2012.

[40] P. S. Prevéy, "X-ray diffraction characterization of crystallinity and phase composition in plasma-sprayed hydroxyapatite coatings," Journal of Thermal Spray Technology, vol. 9, no. 3, pp. 369-376, 2000.

[41] I. Bertóti, "Characterization of nitride coatings by XPS," Surface and Coatings Technology, vol. 151-152, pp. 194-203, 2002.

[42] J. Baranowska and S. E. Franklin, "Characterization of gasnitrided austenitic steel with an amorphous/nanocrystalline top layer," Wear, vol. 264, no. 9-10, pp. 899-903, 2008. 
[43] G. N. Mu, T. P. Zhao, M. Liu, and T. Gu, "Effect of metallic cations on corrosion inhibition of an anionic surfactant for mild steel," Corrosion, vol. 52, no. 11, pp. 853-856, 1996.

[44] A. K. Singh and M. A. Quraishi, "Inhibitive effect of diethylcarbamazine on the corrosion of mild steel in hydrochloric acid," Corrosion Science, vol. 52, no. 4, pp. 1529-1535, 2010.

[45] A. Popova, M. Christov, S. Raicheva, and E. Sokolova, "Adsorption and inhibitive properties of benzimidazole derivatives in acid mild steel corrosion," Corrosion Science, vol. 46, no. 6, pp. 1333-1350, 2004. 

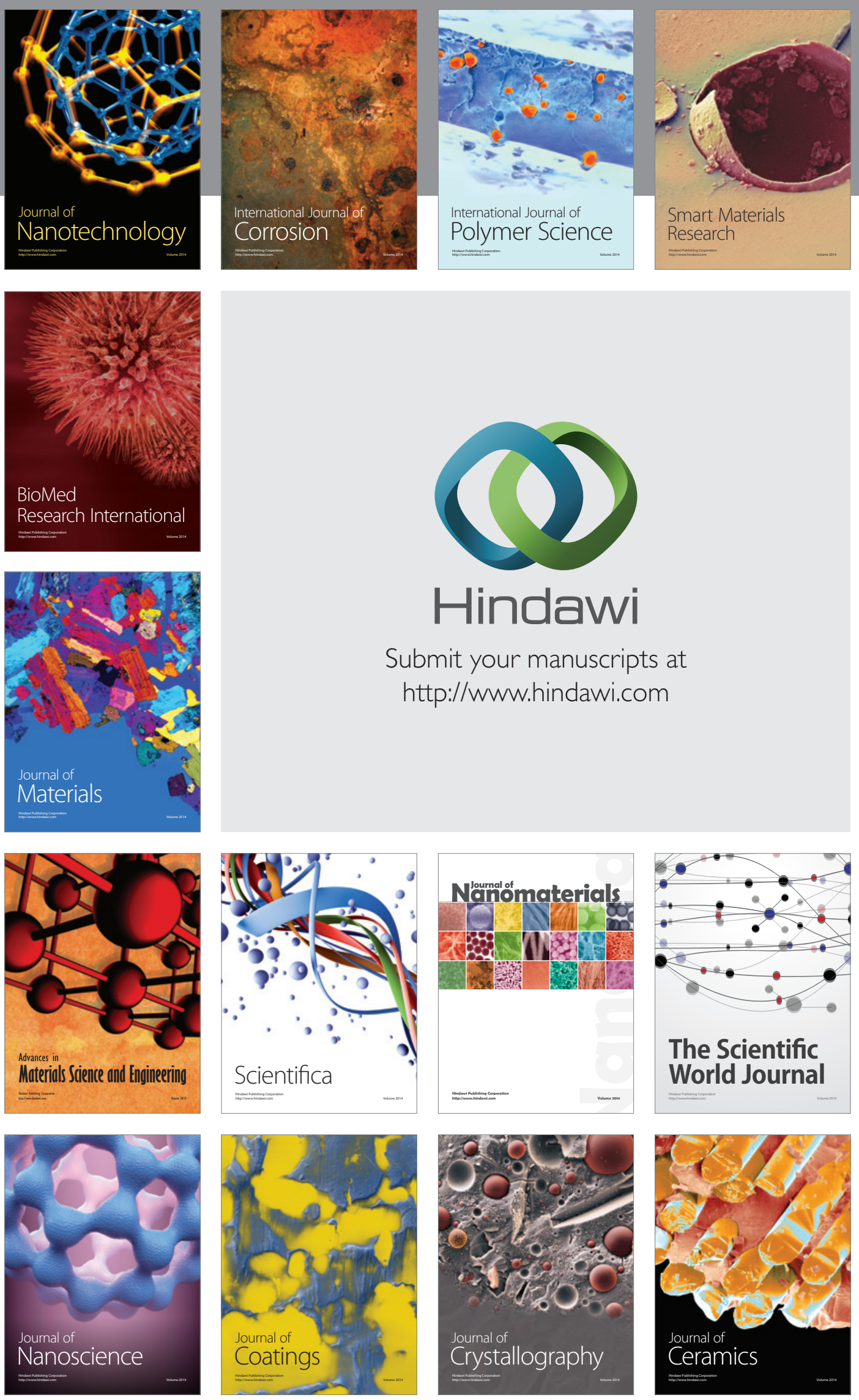

The Scientific World Journal

Submit your manuscripts at

http://www.hindawi.com

\section{World Journal}

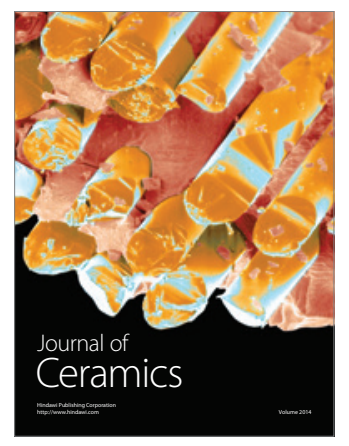

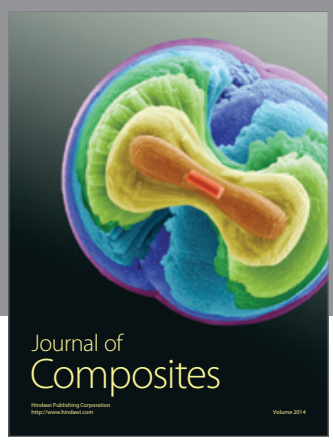
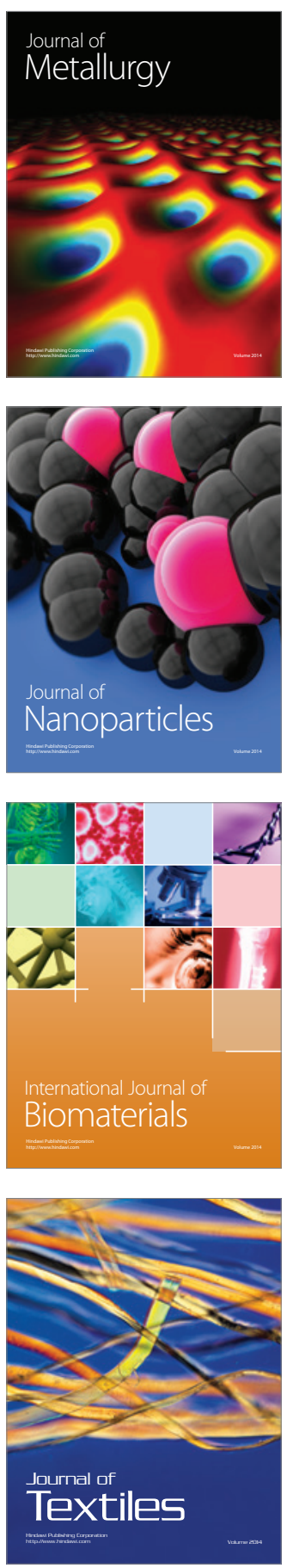